\title{
An Effective Core Potential Study of Transition-Metal Chalcogenides. 1. Molecular Structure
}

\author{
Michael T. Benson, Thomas R. Cundari, ${ }^{, 1}$ Soon J. Lim, Hoang D. Nguyen, and \\ Karen Pierce-Beaver
}

Contribution from the Department of Chemistry, Memphis State University, Memphis, Tennessee 38152

Received November 22, $1993^{\circ}$

\begin{abstract}
A structural analysis is reported of roughly 150 transition-metal (TM)-chalcogenido complexes in a variety of chemical environments. With few exceptions, agreement between calculated and experimental geometries is excellent. The research provides convincing evidence that computational methods employed are adequately describing the bonding in these diverse TM complexes. Interesting trends in relative $T M C h\left(R_{M C h}-R_{M C h}\right)$ bond lengths are found. Experimental and computational data show that other than the zirconocene- and hafnocene-oxos there is similar behavior in relative bond lengths for widely varying TM-chalcogenido complexes. Relative bond lengths versus oxo ( $\mathrm{S}-\mathrm{O}$, Se-O, and $\mathrm{Te}-\mathrm{O}$ ) in group IVB metallocenes tend to be larger than for other families of complexes and show less variation among the heavier chalcogens (Se-S, Te-S, and Te-Se). Analysis of localized wave functions for $\mathrm{Cp}_{2} \mathrm{ZrCh}$ point to a greater contribution from a singly-bonded $\mathrm{Zr}-\mathrm{Ch}$ structure (relative to $\mathrm{Zr}=\mathrm{Ch}$ ) when $\mathrm{Ch}$ is $\mathrm{O}$ compared to heavier chalcogens. Taken together, the data suggest that there is a fundamental difference in the $\mathrm{Zr}-\mathrm{oxo}$ (and $\mathrm{Hf}-\mathrm{oxo}$ ) bond in relation to heavier chalcogens, consistent with recent experimental data. In previous studies of multiply bonded TM complexes we have focused on the ability of ECPs to make computations feasible for complexes incorporating even the heaviest transition metals. The present work also evaluates ECP methods for heavier main group (MG) elements. The chalcogens (Ch) O, S, Se, and Te are included in this study.
\end{abstract}

\section{Introduction}

Among complexes with a multiple bond between a transitionmetal (TM) and main group (MG) element, chalcogens (Ch) are probably the most studied in terms of molecular and vibrational structure, particularly for the lightest member of the series-oxo $\left(\mathrm{L}_{n} \mathrm{M}=\mathrm{O}\right)$ complexes. An overview of oxo structure and bonding can be found in reviews by Mayer and Nugent, ${ }^{2}$ Griffith, ${ }^{3}$ and Holm. ${ }^{4}$ Müller has reviewed $d^{0}$ sulfidos and selenidos. ${ }^{5}$ Roof and Kolis have recently reviewed the literature for selenido and tellurido complexes including some terminally-bound examples. ${ }^{6}$ Oxo complexes have received the most attention, because of their intermediacy in biochemical (e.g., cytochrome P-4507) and industrial (e.g., conversion of propylene to acrolein ${ }^{8}$ ) oxidations. Apart from fundamental interest in $\mathrm{TM}=\mathrm{MG}$ multiple bonding for heavier main group elements, TM-chalcogen complexes have received attention in connection with the design of molecular precursors to solid-state materials. ${ }^{9}$ Terminal sulfidos are of interest in connection with biochemical systems such as xanthine oxidase. ${ }^{10}$ Recent synthetic efforts have produced the first terminally-bound tellurido complex by Rabinovich and Parkin, ${ }^{11}$ trans-W( $\left(\mathrm{PMe}_{3}\right)_{4}(\mathrm{Te})_{2}$, which was quickly followed by examples

- Abstract published in Advance ACS Abstracts, March 15, 1994.

(1) e-mail:cundarit @ memstvx1.memst.edu.

(2) Nugent, W. A.; Mayer, J. M. Metal-Ligand Multiple Borids; Wiley:

New York, 1988.

(3) Griffith, W. P. Coord. Chem. Rev. 1970, 5, 459.

(4) Holm, R. H. Chem. Rev. 1987, 87, 1401.

(5) (a) Diemann, Müller, A. Coord. Chem. Rev. 1973, 10, 79. (b) Müller,

A.: Diemann, E. In Comprehensive Coordination Chemistry; Wilkinson, G

Gillard, R. D., McCleverty, J. A., Eds.; Vol. 2, Pergamon: New York, 1987.

(6) Roof, L. C.; Kolis, J. W. Chem. Rev. 1993, 93, 1037.

(7) Cytochrome P-450; Ortiz de Montellano, P. R., Ed.; Plenum: New York, 1986.

(8) Mitchell, P. C. H.; Trifiro, F. J. Chem. Soc., A 1970, 3183.

(9) Brennan, J. G.; Siegrist, T.; Carroll, P. J.; Struczynski, S. M.; Reynders, P.; Brus, L. E.; Steigerwald, M. L. Chem. Mater. 1990, 2, 403.

(10) Eagle, A. A.; Laughlin, L. J.; Young, C. G.; Tiekint, E. R. T. J. Am Chem. Soc. 1992, 114, 9195.

(11) Rabinovich, D.; Parkin, G. J. Am. Chem. Soc. 1991, 113, 9421. from Christou and Arnold: $\mathrm{Zr}$ and $\mathrm{Hf}(\mathrm{Te})(\text { sitel })_{2}$ (dmpe $)_{2}$, sitel $=\mathrm{TeSi}\left(\mathrm{SiMe}_{3}\right)_{3} ;$ dmpe $=1,2-$ bis (dimethylphosphino)ethane..$^{12}$ Howard and Parkin have reported an entire series of chalcogenido complexes $\mathrm{Cp}_{2}{ }_{2} \mathrm{M}(\mathrm{Ch})(\mathrm{py})$ for $\mathrm{M}=\mathrm{Zr}$ and $\mathrm{Hf}, \mathrm{Ch}=\mathrm{O}, \mathrm{S}, \mathrm{Se}$, $\mathrm{Te} ; \mathrm{Cp}^{\prime}=\eta^{5}-\mathrm{C}_{5} \mathrm{Me}_{4} \mathrm{Et} ; \mathrm{py}=$ pyridine. ${ }^{13}$ Page et al. have published electron diffraction studies of $\mathrm{W}(\mathrm{X})_{4}(\mathrm{Ch}), \mathrm{X}=\mathrm{F}, \mathrm{Br}, \mathrm{Cl}$ and $\mathrm{Ch}$ $=\mathrm{O}, \mathrm{S}, \mathrm{Se} .^{14}$ Finally, there are the well-known metallates, $\left[\mathrm{MO}_{4}\right]^{\mathfrak{q}-}$, as well as sulfido and selenido congeners. ${ }^{2-5}$

The present contribution is a continuation of computational studies of $\mathrm{TM}=\mathrm{MG}$ bonding, ${ }^{15}$ the focus of which is developing computational approaches to complexes incorporating metals from the entire d-block. Two main questions are addressed in this paper. First, are computational methods capable of predicting the structure of TM chalcogenido complexes? In previous studies we have employed effective core potential (vide infra) methods to study multiple bonding; with few exceptions we have found the computational scheme to perform quite well with respect to structural prediction. ${ }^{15}$ Second, what approaches are appropriate to the chemistry of the heavier MG elements? In previous work we have sought to highlight opportunities methodological advances provide in the study of the heaviest TMs. ${ }^{15}$ Chalcogenido complexes provide an excellent opportunity to explore the heavier

(12) Christou, V.; Arnold, J. J. Am. Chem. Soc. 1992, 114, 6240.

(13) (a) $\mathrm{Zr}$; Howard, W. A.; Parkin, G, J. Am. Chem. Soc. In press. (b) Hf: Howard, W. A.; Parkin, G. J. Organomet. Chem. Submitted.

(14) Page, E. M.; Rice, D. A.; Hagen, K.; Hedberg, L.; Hedberg, K. Inorg. Chem. 1991, 30, 4758.

(15) To date $\mathrm{L}_{n} \mathrm{M}=\mathrm{NR},{ }^{15 a} \rightarrow \mathrm{L}_{n} \mathrm{M}=\mathrm{C}(\mathrm{R}) \mathrm{R}^{\prime},{ }^{15 t-\mathrm{h}} \mathrm{L}_{n} \mathrm{M}=\mathrm{Si}(\mathrm{R}) \mathrm{R}^{\prime},{ }^{15 i \mathrm{j}}$ and $\mathrm{L}_{n} \mathrm{M}=\mathrm{PR}^{15 \mathrm{k}}$ complexes have been the focus of computational studies. (a) Cundari, T. R. J. Am. Chem. Soc. 1992, 114, 7879. (b) Cundari, T. R. J. Am. Chem. Soc. 1992, 114, 10557. (c) Cundari, T. R. Organometallics 1993, 12,1998. (d) Cundari, T. R. Intern. J. Quantum Chem., Proc. Sanibel Symp. 1992, 26, 793. (e) Cundari, T. R. Organometallics Submitted. (f) Cundari, T. R.; Gordon, M. S. J. Am. Chem. Soc. 1991, 113, 5231. (g) Cundari, T. R.; Gordon, M. S. J. Am. Chem. Soc. 1992, I14, 539. (h) Cundari, T. R.; Gordon, M. S. Organometallics 1992, 11,55 . (i) Cundari, T. R.; Gordon, M. S. Organometallics 1992, 11,3122 . (j) Cundari, T. R.; Gordon, M. S. J. Phys. Chem. 1992, 96, 631. (k) Benson, M. T.; Cundari, T. R.; Li, Y.; Strohecker, L. A. Intern J. Quantum Chem., Proc. Sanibel Symp. In press. 
MG elements. In addition to the large database of structural information, chalcogenido complexes are one of the few families of TM complexes for which there is extensive vibrational data for complexes in varied chemical environments, ${ }^{2-6}$ bringing us to a third point of interest, to be addressed in a companion paper. Can a simple computational scheme predict the vibrational structure of TM complexes? Ab initio methods have been successfully applied to estimation of vibrational spectra for main group bonds..$^{16}$ However, to our knowledge, no systematic investigation for a family of related TM complexes has been reported. In the present contribution the focus is on the bonding and structure of chalcogenidos with relatively simple ligand sets (e.g., halides) that have been the subject of structural and/or vibrational analysis.

\section{Computational Methods}

Calculations employ the program GAMESS running in serial, parallel, and vector mode. ${ }^{17}$ An iPSC/860 (Oak Ridge National Lab), Paragon (San Diego Supercomputing Center, SDSC), CM-5 (University of Tennessee-Knoxville), and SP-1 (Cornell National Supercomputer Facility) were used as parallel platforms. Calculations also employed vectorized GAMESS on the Cray Y-MP/868 at SDSC and the serial version of GAMESS at Memphis State (RS-6000/350).

Our main approach to the challenges of computational d- and f-block chemistry is the design and testing of effective core potentials (ECPs)..$^{18}$ Great savings in time, memory, and disk space are effected by replacing chemically less important core electrons and orbitals with a small number of ECPs. Effective core potentials (ECPs) and valence basis sets are used for heavy atoms and the $-31 \mathrm{G}$ basis set for H. ECPs replace the innermost core orbitals for the TMs and all core orbitals for main-group (MG) elements. ${ }^{18}$ Thus, the ns, np, nd, $(n+1)$ s, and $(n+1)$ p are treated explicitly for the d-block; ${ }^{18 \mathrm{a}}$ for the main-group, ns and np are treated explicitly. ${ }^{18 \mathrm{~b}}$ In the standard implementation, TM valence basis sets are quadruple- and triple- $\zeta$ for the sp and d shells, respectively, while maingroup elements have a double- $\zeta$ valence basis. ${ }^{18 a, b}$ Basis sets for MG elements are augmented with a d polarization function. ${ }^{19}$ Bond lengths and angles for $\mathrm{TM}=\mathrm{MG}$ complexes are typically predicted to within $1-3 \%$ of experiment using the present scheme. ${ }^{15}$ From a chemical standpoint, ECPs afford great leeway in the choice of interesting problems since calculations on congeners within a group are carried out with near equal facility.

Geometries are optimized at the restricted Hartree-Fock (RHF) level for closed-shell singlets, unless otherwise specified; for open-shell systems a restricted open-shell Hartree-Fock wave function (ROHF) is used. Vibrational frequencies are calculated at stationary points to identify them as minima or transition states. Intrinsic stretching frequencies, and force constants derived from them, were calculated using the method of Boatz and Gordon. ${ }^{20}$

\section{Results}

1. Geometries. a. $\mathbf{L}_{n} \mathbf{M}(\mathrm{Ch})$ Complexes. Mono oxo complexes come in a wide variety of oxidation states, ligand sets, and coordination geometries with structurally characterized examples ranging from the $\mathrm{Ti}^{2,13}$ to Co-triad. ${ }^{21}$ This richness of chemical environments is an ideal test for flexibility of the ECP scheme. A preliminary study using the present ECP approach has been

(16) Pople, J. A.; Schlegel, H. B.; Krishnan, R.; DeFrees, D. F.; Binkley, J. S.; Frisch, M. J.; Whiteside, R.; Hout, R. F.; Hehre, W. J. Int. J. Quantum Chem., Proc. Sanibel Symp. 1981, 15, 269.

(17) Details concerning the parallel implementation of GAMESS are given: Schmidt, M. W.; Baldridge, K. K.; Boatz, J. A.; Jensen, J. H.; Koseki, S.; Matsunaga, N.; Gordon, M. S.; Nguyen, K. A.; Su, S.; Windus, T. L.; Elbert, S. T.; Montgomery, J.; Dupuis, M. J. Comput. Chem. 1993, 14, 1347. (18) (a) Krauss, M.; Stevens, W. J.; Basch, H.; Jasien, P. G. Can. J. Chem. 1992, 70, 612. (b) Stevens, W. J.; Basch, H.; Krauss, M. J. Chem. Phys. 1984, 81, 6026. (c) Cundari, T. R.; Stevens, W. J. J. Chem. Phys. 1993, 98, 5555 .

(19) Pople, J. A.; Hehre, W. J.; Radom, L.; Schleyer, P. v. R. Ab-Initio Molecular Orbital Theory; Wiley: New York, 1986.

(20) Boatz, J. A.; Gordon, M. S. J. Phys. Chem. 1989, 93, 1819.

(21) Wilkinson, G.; Motherwell, R. S.; Hussain-Bates, B.; Hursthouse, M. B. Polyhedron 1993, 12, 2009. reported for $\mathrm{Re}-\mathrm{oxos} ; 22$ formal oxidation states of the Re-oxo complexes are $+1,+3,+5$, and +7 , and coordination numbers (counting acetylene as a monodentate ligand) range from 3 to 6 , A-D. Parallel-GAMESS and

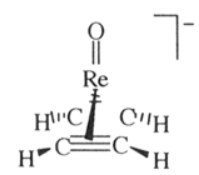

$\mathbf{A}$

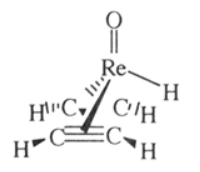

B

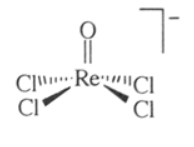

C

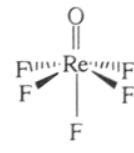

D
ECP methods quickly predicted bond lengths and bond angles of these chemically distinct $\mathrm{Re}-0 x$ o complexes to within a few hundredths of an $\AA$ and $3^{\circ}$ (i.e., errors of only $1-3 \%$ ), respectively. ${ }^{22}$ A more systematic study of the major structural motifs for chalcogenido complexes is given below.

i. $\mathbf{M X}_{2} \mathbf{C h}$ Complexes. The low coordination number of an $\mathrm{MX}_{2} \mathrm{Ch}$ complex is expected to limit structurally characterized examples to systems where $\mathrm{X}$ is bulky enough to engender kinetic stability. Examples of the $\mathrm{MX}_{2} \mathrm{Ch}$ structural motif are $\mathrm{Cp}^{\prime}{ }^{-}$ $\mathrm{MCh}$ where $\mathrm{M}$ is a group IVB ( $\mathrm{Ti}, \mathrm{Zr}, \mathrm{Hf}$ ) metal. ${ }^{13,23-28}$ Structurally characterized complexes have a fourth (py or substituted-py) ligand, although there is evidence that transient $\mathrm{Cp}_{2}{ }_{2} \mathrm{MCh}$ is formed in solution. ${ }^{25-27}$ The complexes $\mathrm{Zr}$ and $\mathrm{Hf}-$ (Te)(sitel $)_{2}$ can be considered as being of the $\mathrm{MX}_{2} \mathrm{Ch}$ type with two bidentate dmpe ligands coordinated for a total coordination number of 7.12 At an opposite extreme from high-valent, Titriad chalcogenides are bis(alkyne) Re-oxo anions which were first isolated as $\left[\mathrm{Na}(\mathrm{MeCN})_{2}\right]^{+}$-bridged dimers ${ }^{29}$ and recently in monomeric form by sequestering the $\mathrm{Na}^{+}$counter ion in a cryptand. ${ }^{22}$ A more indepth ECP analysis of $\left[\mathrm{Re}(\mathrm{O})(\mathrm{HCCH})_{2}\right]^{-}$ has been published elsewhere. ${ }^{22}$

Until recently, there have been few structurally characterized, terminal chalcogenidos of group IVB metals. ${ }^{13}$ The main examples were limited to titanyl complexes of porphyrin and porphyrin-like ligands. ${ }^{30-36}$ Andersen et al. have structurally characterized $\mathrm{Cp}^{*}{ }_{2} \mathrm{Ti}(\mathrm{O})\left(4-\right.$ phenyl-py). ${ }^{23}$ The availability of parallel computing resources makes feasible a study of metallocene models $\left(\mathrm{Cp}_{2} \mathrm{M}(\mathrm{Ch})\right), \mathrm{M}=\mathrm{Ti}, \mathrm{Ch}=\mathrm{O} ; \mathrm{M}=\mathrm{Zr}, \mathrm{Hf} ; \mathrm{Ch}=\mathrm{O}$, $\mathrm{S}, \mathrm{Se}, \mathrm{Te}$. Metallocene models, $\mathbf{1}$,

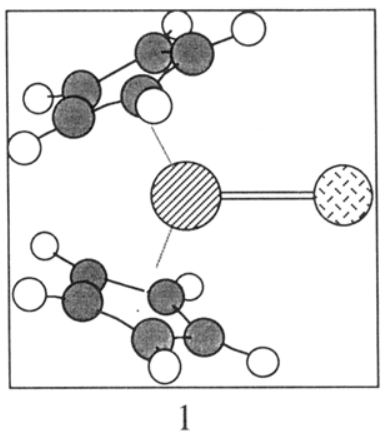

were optimized under $C_{2 v}$ symmetry; results are collected in Table

(22) Cundari, T. R.; Critchlow, S. C.; Conry, R. R.; Spaltenstein, E.; Hall,

K. A.; Tahmassebi, S.; Mayer, J. M. Organometallics 1994, 13, 322.

(23) Smith, M. R.; Matsunaga, P. T.; Andersen, R. A. J. Am. Chem. Soc, 1993, 115, 7049 .

(24) Howard, W. A.; Waters, M.; Parkin, G. J. Am. Chem. Soc. 1993, 115, 4917.

(25) Carney, M. J.; Walsh, P. J.; Hollander, F. J.; Bergman, R. G. Organometallics 1992, 11, 761.

(26) Carney, M. J.; Walsh, P. J.; Hollander, F. J.; Bergman, R. G. J. Am. Chem. Soc. 1989, 111, 8751.

(27) Carney, M. J.; Walsh, P. J.; Bergman, R. G. J. Am. Chem. Soc. 1990, 112,6426 .

(28) A zirconyl complex not based on the $\mathrm{Cp}^{\prime}{ }_{2} \mathrm{M}(\mathrm{Ch})(\mathrm{py})$ motif is given: Jacoby, D.; Floriani, C.; Chiesi-Villa, A.; Rizzoli, C. J. Am. Chem. Soc. 1993, 115,7025 .

(29) Spaltenstein, E.; Conry, R. R.; Critchlow, S. C.; Mayer, J. M. J. Am. Chem. Soc. 1989, 111, 8741-8742. 
Table 1. $\mathrm{Cp}_{2} \mathrm{M}(\mathrm{Ch})$ Complexes

\begin{tabular}{lccccccccc}
\hline & $\mathrm{Ti} / \mathrm{O}^{a}$ & $\mathrm{Zr} / \mathrm{O}$ & $\mathrm{Zr} / \mathrm{S}$ & $\mathrm{Zr} / \mathrm{Se}$ & $\mathrm{Zr} / \mathrm{Te}$ & $\mathrm{Hf} / \mathrm{O}$ & $\mathrm{Hf} / \mathrm{S}$ & $\mathrm{Hf} / \mathrm{Se}$ & $\mathrm{Hf} / \mathrm{Te}$ \\
\hline $\mathrm{M}-\mathrm{Ch}$ & $1.61 \AA$ & $1.76 \AA$ & $2.28 \AA$ & $2.42 \AA$ & $2.68 \AA$ & $1.76 \AA$ & $2.28 \AA$ & $2.41 \AA$ & $2.67 \AA$ \\
$\mathrm{M}-\mathrm{Cp}^{b}$ & $2.15 \AA$ & $2.34 \AA$ & $2.29 \AA$ & $2.29 \AA$ & $2.27 \AA$ & $2.31 \AA$ & $2.27 \AA$ & $2.26 \AA$ \\
$\mathrm{Cp}-\mathrm{M}^{\mathrm{C}}-\mathrm{Cp}$ & $132^{\circ}$ & $131^{\circ}$ & $131^{\circ}$ & $131^{\circ}$ & $132^{\circ}$ & $131^{\circ}$ & $131^{\circ}$ & $131^{\circ}$ & $133^{\circ}$ \\
$\nu_{\mathrm{MCh}^{c}}$ & 1059 & 945 & 484 & 328 & 248 & 933 & 462 & 293 & 213 \\
$k_{\mathrm{MCh}^{c}}$ & 7.92 & 7.15 & 3.25 & 2.68 & 1.92 & 7.53 & 3.42 & 2.80 & 2.01 \\
\hline
\end{tabular}

${ }^{a}$ Geometries of these models, 1 , were calculated as described in the Computational Methods section. ${ }^{6}$ The centroid of the $\eta^{5}-\mathrm{C}_{5} \mathrm{H}_{5}$ ring is denoted Cp. ${ }^{c}$ Intrinsic stretching frequencies $\left(\nu_{\mathrm{MCh}}\right.$, in $\left.\mathrm{cm}^{-1}\right)$ and $\mathrm{MCh}$ force constants $\left(k_{\mathrm{MCh}}\right.$, in mdyn $\left.\AA^{-1}\right)$ are calculated using the method of Boatz and Gordon. ${ }^{20}$

1. The $\mathrm{Ti}-$ oxo bond length in $\mathrm{Cp}_{2} \mathrm{TiO}$ is $1.61 \AA$, in good agreement with $\mathrm{Cp}_{2}{ }_{2} \mathrm{Ti}(\mathrm{O})$ (4-phenyl-py) which has a $\mathrm{TiO}$ bond length of $1.665(3) \AA .{ }^{23}$ Titanium-oxo bond lengths from $1.613(5) \AA$ to 1.653(3) $\AA$ have been reported for other titanyl complexes. ${ }^{30-34}$ The $\mathrm{Ti}-\mathrm{Cp}\left(\mathrm{Cp}\right.$ is the centroid of the $\eta^{5}-\mathrm{C}_{5} \mathrm{H}_{5}$ ring) distance in $\mathrm{Cp}_{2} \mathrm{TiO}$ is $2.15 \AA$, compared to $2.20 \AA$ in $\mathrm{Cp}^{*}{ }_{2} \mathrm{Ti}(\mathrm{O})$ (4-phenylpy).

A preliminary account of ECP studies of $\mathrm{CpM}(\mathrm{Ch})$ complexes can be found in refs $13 a$ and $13 b$ along with metric data for experimental models. As noted, ${ }^{13}$ there is excellent agreement between calculated and experimenta ${ }^{13}\left(\left(\mathrm{Cp}^{\prime}\right){ }_{2} \mathrm{M}(\mathrm{py})(\mathrm{Ch})\right.$ in parentheses) $\mathrm{ZrCh}$ and $\mathrm{HfCh}$ bond lengths: $\mathrm{ZrO}=1.76 \AA$ (1.804(4) $\AA), \mathrm{ZrS}=2.28 \AA$ (2.334(2) $\AA), \mathrm{ZrSe}=2.42 \AA(2.480(1)$ $\AA)$, and $\mathrm{ZrTe}=2.68 \AA$ (2.729 (1) $\AA) ; \mathrm{HfO}=1.76 \AA$ (1.826(9) $\AA) ; \mathrm{HfS}=2.28(2.311(3) \AA) ; \mathrm{HfSe}=2.41 \AA$ (2.467(1) $\AA$ ); HfTe $=2.67 \AA(2.716(1) \AA)$, an average difference of only $2 \%$ for the entire series. Trends in bond lengths also show excellent agreement, e.g., $\mathrm{ZrS}-\mathrm{ZrO}=0.52 \AA(0.53 \AA$, experimental $), \mathrm{ZrSe}-$ $\mathrm{ZrO}=0.66 \AA(0.68 \AA$, experimental $), \mathrm{ZrTe}-\mathrm{ZrO}=0.92 \AA(0.93$ $\AA$, experimental). Calculated $\mathrm{Zr}-\mathrm{Cp}$ distances are $\approx 2.3 \AA$ for 1 , as found experimentally; ${ }^{13}$ similar good agreement is found for hafnocenes. The excellent results for a series of calculations ranging from a $\mathrm{TiO}$ analogue to its $\mathrm{HfTe}$ congener, obtained with equal computational facility, is a powerful exhibition of the utility of ECP methods in accessing chemistry of the entire Periodic Table.

ii. $\mathbf{M}(\mathbf{X})_{3}$ Ch Complexes. Four-coordinate oxos are not prevalent; in the compendium of Nugent and Mayer ${ }^{2}$ the only structurally characterized examples are $\mathrm{VCl}_{3} \mathrm{O}$ and $\mathrm{Ta}(\mathrm{O})[\mathrm{N}(\mathrm{i}$ $\left.\mathrm{Pr})_{2}\right]_{3}$. The complex $\mathrm{VCl}_{3} \mathrm{O}$ has been studied by gas-phase electron diffraction: ${ }^{37} \mathrm{VO}=1.56(4) \AA(1.50 \AA$, calcd $) ; \mathrm{VCl}=2.12(3) \AA$ (2.14, calcd); $\mathrm{OVCl}=108(2)^{\circ}\left(109^{\circ}\right.$, calcd $)$. Complexes of $\mathrm{NbOCl}_{3}$ with two neutral bases have been characterized; ${ }^{38} \mathrm{NbO}$ bonds in mer- $\mathrm{Nb}(\mathrm{O})(\mathrm{Cl})_{3}(\mathrm{hmpa})_{2}$ and mer- $\mathrm{Nb}(\mathrm{O})(\mathrm{Cl})_{3}(\mathrm{MeCN})_{2}$ are $1.692(5) \AA$ and $1.68(2) \AA$, consistent with the calculated value of $\mathrm{NbO}=1.65 \AA$ in the $C_{3 v}$ minimum of $\mathrm{NbCl}_{3} \mathrm{O}$. The calculated $\mathrm{TaO}$ bond length in $\mathrm{TaCl}_{3} \mathrm{O}, 1.67 \AA$, is shorter by $3 \%$ than the $\mathrm{TaO}$ bond length in $\mathrm{TaO}\left(\mathrm{N}(\mathrm{i}-\mathrm{Pr})_{2}\right)_{3}, 1.725(7) \AA .{ }^{2}$

(30) Dwyer, P. N.; Puppe, L.; Buchler, J. W.; Scheidt, W. R. Inorg. Chem. $1975,14,1782$

(31) Guilard, R.; Latour, J. M.: Lecomte, C.; Marchon, J. C.; Protas, J.; Ripoll, D. Inorg. Chem. 1978, 17, 1228.

(32) Hiller, W.; Strähle, J.; Kobel, W.; Hanack, M. Z. Kristollogr. 1982, 159,173 quoted in ref $2, p 193$. 235 .

(34) Bodner, A.; Jeske, P.; Weyhermüller, T.; Weighardt, K.; Dubler, E.; Schmalle, H.; Nuber, B. Inorg. Chem. 1992, 31, 3737.

(35) (a) Housmekerides, C. E.; Ramage, D. L.; Cretz, C. M.; Shontz, J. T.; Pilato, R. S.; Geoffrey, G. L.; Rheingold, A. L.; Haggerty, B. S. Inorg. Chem. 1992, 31, 4453. (b) Housmekerides, C. E.; Pilato, R. S.; Geoffrey, G. L.; Rheingold, A. L.; Haggerty, B. S. J. Chem. Soc., Chem. Commun. 1991 563.

(36) An interesting example of a titanyl complex without a porphyrin-like base is provided by Peng-Ju and co-workers on $\left[\mathrm{Ti}(\mathrm{O})\left(\mathrm{CO}_{3}\right)_{3}\right]^{4}$. Peng-Ju, L.; Sheng-Hua, H.; Kun-Yao, H.; Ru-Ji, W.; Mak, C. W. Inorg. Chem. Acta $1990,175,105$

(37) Palmer, K. J. J. Am. Chem. Soc. 1938, 60, 2360.

(38) Hubert-Pfalzgraf; L. G.; Pinkerton, A. A. Inorg. Chem. 1977, 16, 1895 .
$\mathrm{MX}_{3} \mathrm{~S}$ complexes, $\mathrm{X}=$ halide, have been structurally characterized with additional ligands coordinated to the TM, Table 2. The complexes $\mathrm{MCl}_{3} \mathrm{~S}\left(\mathrm{MCl}_{3} \mathrm{~S}(\mathrm{M}=\mathrm{V}, \mathrm{Nb}, \mathrm{Ta})\right.$ possess $C_{3 v}$ minima and calculated TM-sulfido bond lengths of $1.94 \AA(V)$, $2.11 \AA(\mathrm{Nb})$ and $2.12 \AA(\mathrm{Ta})$. The VIV complex VS(acen), acen $=N, N^{\prime}$-ethylenebis (acetylacetone iminate), has VS $=2.061(1)$ $\AA,{ }^{39}$ considerably longer than in $\mathrm{VCl}_{3} \mathrm{~S}$ probably due in part to the change in oxidation state. The $\mathrm{SPPh}_{3}$ adduct of $\mathrm{NbCl}_{3} \mathrm{~S}$ has $\mathrm{Nb}$-sulfido $=2.114$ (4) $\AA$, very close to the calculated value; the $\mathrm{SPPh}_{3}$ ligand in this adduct is trans to the sulfido making it unclear to what extent this lengthens the $\mathrm{Nb}$-sulfido bond over that in a base-free complex. ${ }^{40}$ The calculated $\mathrm{TaS}$ bond length of $2.12 \AA$ in $\mathrm{TaCl}_{3} \mathrm{~S}$ is shorter than the average of the eight reported terminal $\mathrm{Ta}^{\mathrm{v} S}$ bond lengths, $2.18 \AA,\left(\mathrm{Ta}(\mathrm{S})(\mathrm{Cl})_{3}\right.$ $\left(\mathrm{PhSCH}_{2} \mathrm{CH}_{2} \mathrm{SPh}\right),{ }^{41} \mathrm{STa}\left(\mathrm{S}_{2} \mathrm{CNEt}_{2}\right)_{3},{ }^{42}$ six terminal $\mathrm{TaS}$ bonds in $\left.\mathrm{Ta}_{6} \mathrm{~S}_{17}{ }^{4}\right),{ }^{43}$ which is not surprising given the larger coordination numbers of experimental models.

Simple $\mathrm{Cl}_{3} \mathrm{TaCh}$ models of recently reported selenido and tellurido complex, $2,{ }^{44}$ were

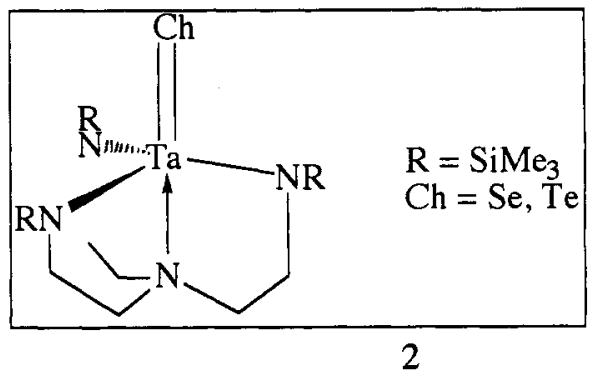

studied. The TaSe and $\mathrm{TaTe}$ bond lengths in $\mathrm{TaCl}_{3} \mathrm{Ch}$ are 2.24 and $2.47 \AA$, respectively, a difference of $0.23 \AA$; experimental bond lengths in 2-Se and 2-Te are 2.330(1) $\AA$ and 2.568(1) $\AA, 44 \mathrm{a}$ a difference of $0.24 \AA$. Using the $\mathrm{Ta}-0 x$ o bond length in $\mathrm{TaCl}_{3} \mathrm{O}$ as a standard, Table 2, shows that ECPs yield excellent reproduction of trends as well as providing quantitative prediction of metric data: $\mathrm{TaS}-\mathrm{TaO}=0.45 \AA(0.45 \AA$, experimental $)$, TaSe$\mathrm{TaO}=0.57 \AA(0.60 \AA$, experimental $), \mathrm{TaTe}-\mathrm{TaO}=0.80 \AA$

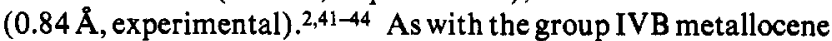
complexes, there is good agreement for TM-chalcogenido bond lengths between computational and experimental models both in absolute and relative terms. Finally, note that TMCh bond length differences relative to the oxo analogue are much higher (by $\approx 0.1 \AA$ ) in the Ta case than in the group IVB systems, a point

(39) Money, J. K.; Huffman, J. C.; Christou, G. Inorg. Chem. 1985, 24, 3297.

(40) Seela, J. L.; Huffman, J. C.; Christou, G. Polyhedron 1989, 8, 1797.

(41) Drew, M. G. B.; Rice, D. A.; Williams, D. M. J. Chem. Soc., Dalton Trans. 1984, 845 .

(42) $\mathrm{TaS}\left(\mathrm{S}_{2} \mathrm{CNEt}\right)_{3}$

(43) Sola, J.; Do, Y.; Berg, J. M.; Holm, R. H. Inorg. Chem. 1985, 24, 1706.

(44) (a) Christou, V.; Arnold, J. Angew. Chem., Int. Ed. Engl. 1993, 32, 1450. (b) The related complexes $2-O$ has been reported as resulting from the reaction of 2-PR $(\mathbf{R}=\mathrm{Cy}, \mathrm{t}-\mathrm{Bu}, \mathrm{Ph}$ ) with carbonyl compounds to produce phosphaalkenes. No structural data was reported. Schrock, R. R.; Cummins, C. C.; Davis, W. M. Angew. Chem., Int. Ed. Engl. 1993, 32, 756. 
Table 2. $\mathrm{MCl}_{3} \mathrm{Ch}$ Complexes ${ }^{a}$

\begin{tabular}{lcccccccc}
\hline & $\mathrm{V} / \mathrm{O}$ & $\mathrm{Nb} / \mathrm{O}$ & $\mathrm{Ta} / \mathrm{O}$ & $\mathrm{V} / \mathrm{S}$ & $\mathrm{Nb} / \mathrm{S}$ & $\mathrm{Ta} / \mathrm{S}$ & $\mathrm{Ta} / \mathrm{Se}$ & $\mathrm{Ta} / \mathrm{Te}$ \\
\hline $\mathrm{M}-\mathrm{Ch}$ & $1.50 \AA$ & $1.65 \AA$ & $1.67 \AA$ & $1.94 \AA$ & $2.11 \AA$ & $2.12 \AA$ & $2.24 \AA$ \\
$\mathrm{M}-\mathrm{Cl}$ & $2.14 \AA$ & $2.31 \AA$ & $2.31 \AA$ & $2.14 \AA$ & $2.30 \AA$ & $2.30 \AA$ & $2.30 \AA$ \\
$\mathrm{Ch}-\mathrm{M}-\mathrm{Cl}$ & $109^{\circ}$ & $108^{\circ}$ & $108^{\circ}$ & $109^{\circ}$ & $108^{\circ}$ & $109^{\circ}$ & $110^{\circ}$ & $2.47 \AA$ \\
$\nu_{\mathrm{MCh}}{ }^{\circ}$ & 1286 & 1143 & 1132 & 712 & 629 & 592 & 392 \\
$k_{\mathrm{MCh}^{b}}$ & 11.86 & 10.50 & 11.10 & 5.86 & 5.55 & 5.61 & 5.02 & 296 \\
\hline
\end{tabular}

${ }^{a}$ All complexes are $C_{3 v}$ minima as shown below. ${ }^{b}$ Intrinsic stretching frequencies $\left(\nu_{\mathrm{MCh}}\right.$, in cm $\left.{ }^{-1}\right)$ and $\mathrm{MCh}$ force constants $\left(k_{\mathrm{MCh}}\right.$, in mdyn $\left.\AA^{-1}\right)$ are calculated using the method of Boatz and Gordon. ${ }^{20}$<smiles>O=[W](Cl)(Cl)Cl</smiles>

that we will return to once more metric data has been collected.

Two of the more interesting oxos which have been recently characterized both possess the $\mathrm{MX}_{3} \mathrm{O}$ motif- $\mathrm{d}^{4}$-tris(mesityl)$\mathrm{Ir}^{\mathrm{V}}-\mathrm{OXO}^{21}$ and $\mathrm{d}^{4}$-bis(acetylene) $\mathrm{Re}^{\mathrm{III}}$-oxo complexes $(\mathbf{B}) .{ }^{45}$ The former is the first structurally characterized $\mathrm{Ir}-$ oxo complex. ${ }^{46}$ Mayer has presented a qualitative molecular orbital analysis of pseudotetrahedral $\mathrm{ReO}$ complexes in order to understand their ability to stabilize low formal oxidation state. ${ }^{45}$ The complex IrMes ${ }_{3} \mathrm{O}$ is $\approx \mathrm{C}_{3}$ with mesityls forming a three-bladed propeller; the lowest energy $\mathrm{C}_{3}$ structure, 3 , of a $\mathrm{IrMe}_{3} \mathrm{O}$ model has a calculated $\mathrm{IrO}$

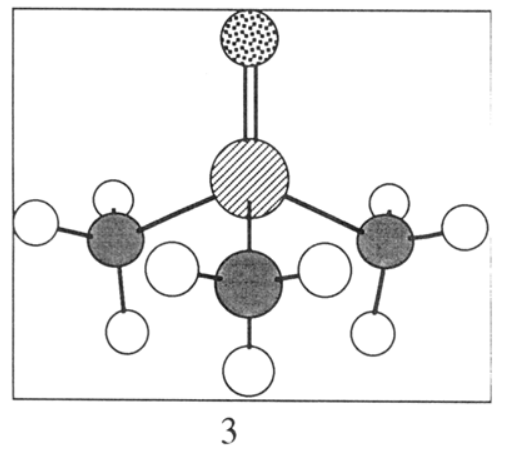

bond length of $1.70 \AA$ in very good agreement with experiment, ${ }^{21}$ $\mathrm{IrO}=1.725(9) \AA$; calculated $\mathrm{Ir}-\mathrm{C}$ bonds $=2.04 \AA$ in 3 and range from 2.00 to $2.03 \AA$ in $\operatorname{IrMes}_{3} \mathrm{O}^{21}$ We have previously compared ECP results for $\left.[\mathrm{Re}(\mathrm{O}) \text { (acetylene })_{2}(\mathrm{H})\right]$ with $\left[\mathrm{Re}(\mathrm{O})(2 \text {-butyne })_{2-}\right.$ (I) $] ;^{22}$ the calculated $\mathrm{Re}$-oxo bond length is $1.71 \AA$, comparing favorably with an experimental bond length of $1.745(7) \AA .{ }^{47}$ The ability of ECPs to predict the structure of these low-valent oxo complexes, in addition to the more common high-valent examples, is encouraging and highlights the need for a flexible scheme to address the wide diversity in TM chemistry.

iii. $\mathbf{M}(\mathbf{X})_{4}(\mathrm{Ch})$ Complexes. Complexes of the type $\mathrm{MX}_{4} \mathrm{Ch}$ almost invariably assume a square-pyramidal geometry, particularly for simple unidentate ligands, ,2,47-62 allowing Ch to occupy

(45) The complex Cp*IrO has been isolated as a dimer. McGhee, W. D.; Foo, T.; Hollander, F. J.; Bergman, R. G. J. Am. Chem. Soc. 1988, 110, 8543. (46) Mayer, J. M.; Thorn, D. L.; Tulip, T. H. J. Am. Chem. Soc. 1985 $107,7454-7462$

(47) Mayer, J. M.; Tulip, T. H.; Calbrese, J. C.; Spaltenstein, E. J. Am. Chem. Soc. 1987, 109, 157.

(48) Fenske, D.; Stahl, K.; Hey, E.; Dehnicke, K. Z. Naturforsch. 1984, $39 B, 850$.

(49) Gahan, B.; Garner, C. D.; Hill, L. H.; Mabbs, F. E.; Hargrave, K. D.; McPhail, A. T. J. Chem. Soc., Dalton Trans. 1977, 1726.

(50) Garner, C. D.; Hill, L. H.; Mabbs, F. E.; McFadden, D. L.; McPhail, A. T. J. Chem. Soc., Dalton Trans. 1977, 1726.

(51) Schumacher, C.; Weller, F.; Dehnicke, K. Z. Anorg. Allg. Chem 1982, 495, 135

(52) Haase, W.; Hoppe, H. Acta Crystallogr. 1968, B24, 282.

(53) Müller, U.; Shihada, A. F.; Dehnicke, K. Z. Naturforsch. 1982, 37 B, 699.

(54) Cotton, F. A.; Davison, A.; Day, V. W.; Gage, L. D.; Trop, H. S. Inorg. Chem. 1979, 18, 3024

(55) Lis, T.; Jezowska-Trzebiatowska, B. Acta Crystallogr. 1977, B33, 1248 . the apical position in the square pyramid and effectively $\pi$-bond to both of the perpendicular metal $\mathrm{d} \pi$ orbitals which are vacant in the high-valent complexes which typify this family. Examples of the $\mathrm{MX}_{4} \mathrm{Ch}$ structural motif are known for the Ti- through Fe-triads with d orbital occupancies of 0,1 , and $2 .^{2}$ A notable counterexample is the $d^{4}$ complex of Mayer et al., $[\operatorname{Re}(\mathrm{O})(2$ butyne $)_{2}$ (bipy) $]^{+} .47$

Comparison of anionic $\mathrm{d}^{1}$ and neutral $\mathrm{d}^{0} \mathrm{MOX}_{4}$ analogues $(\mathrm{M}$ $=\mathrm{Cr}, \mathrm{Mo}, \mathrm{W})$ affords an opportunity to probe oxidation state effects on TMCh multiple bonding and to study the qualitative bonding schemes forwarded for these complexes. The $\mathrm{d}$ orbital splitting diagram of $\mathrm{MOX}_{4}, \mathbf{4}$, is

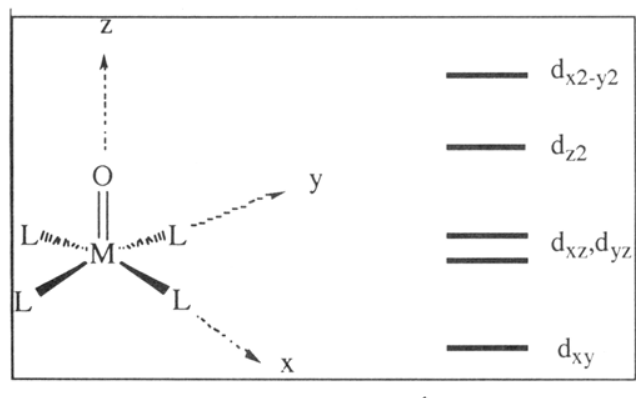

4

similar to that for $\operatorname{MOX}_{5}^{63}$ since orbitals derived from the octahedral $t_{2 g}$ set $\left(\mathrm{d}_{x z}, \mathrm{~d}_{y z}, \mathrm{~d}_{x y}\right.$ in 4$)$ are little affected by removal of a trans ligand. The unpaired electron in $\mathrm{d}^{1}-\mathrm{MOX}_{4}$ should reside in a metal-based, nonbonding orbital. If the $\mathrm{MO}$ vector is the $z$-axis and MX bonds lie in the $x z$ and $y z$ planes, $\mathbf{4}$, the ground state for $\mathrm{d}^{1}-\mathrm{MOX}_{4}$ should have one electron in $\mathrm{d}_{x y}\left({ }^{2} \mathrm{~B}_{2}\right)$. Addition of an electron into $\mathrm{d}_{x y}$ should increase MX bond lengths since this orbital is metal $\mathrm{d} \pi$-halide $\mathrm{p} \pi$ antibonding. The ECP calculations support these conclusions. All $\mathrm{d}^{0}$ and $\mathrm{d}^{1} \mathrm{MOX}_{4}$ complexes described below are $C_{4 v}$ minima with ${ }^{2} \mathrm{~B}_{2}$ ground states for the latter, Table 3. Increases in MX bond lengths are the most noticeable perturbation upon going from $\mathrm{d}^{0}-\mathrm{MOX}_{4}$ to $\mathrm{d}^{1}$ $\left[\mathrm{MOX}_{4}\right]^{-}$. Finally, there are small changes in the metal-oxo linkage; metal-oxo bond lengths are slightly longer in $\mathrm{d}^{1}$ anions than $\mathrm{d}^{0}$ neutrals as expected given the lower oxidation state of the former.

In general, agreement between calculated and experimental ${ }^{48-51}$ geometries is excellent for $C_{4 v} \mathrm{MOX}_{4}{ }^{-}$complexes of the $\mathrm{Cr}$-triad. Metal-oxo bonds tend to be too short by only $1-3 \%$, while metal-

(56) Ijima, K.; Shibata, S. Bull. Chem. Soc. Jpn. 1975, 48, 666

(57) Ijima, K. Bull. Chem. Soc. Jpn. 1977, 50, 373.

(58) Ijima, K. Chem. Lett. 1972, 1033.

(59) Page, E. M.; Rice, D. A.; Hagen, K.; Hedberg, L.; Hedberg, K. Inorg. Chem. 1987, 26, 467.

(60) Hagen, K.; Hobson, R. J.; Rice, D. A.; Turp, N. J. Mol. Struct. 1985, $128,33$.

(61) Hagen, K.; Hobson, R. J.; Holwill, C. J.; Rice, D. A. Inorg. Chem. 1986, 25, 3659 .

(62) Hermann, W. A.; Edu, S. J.; Kiprot, P.; Rypdal, K.; Wetzlowik, P. Angew. Chem., Int. Ed. Engl. 1990, 29, 1445. 
Table 3. $\mathrm{MOX}_{4}$ Complexes ${ }^{a}$

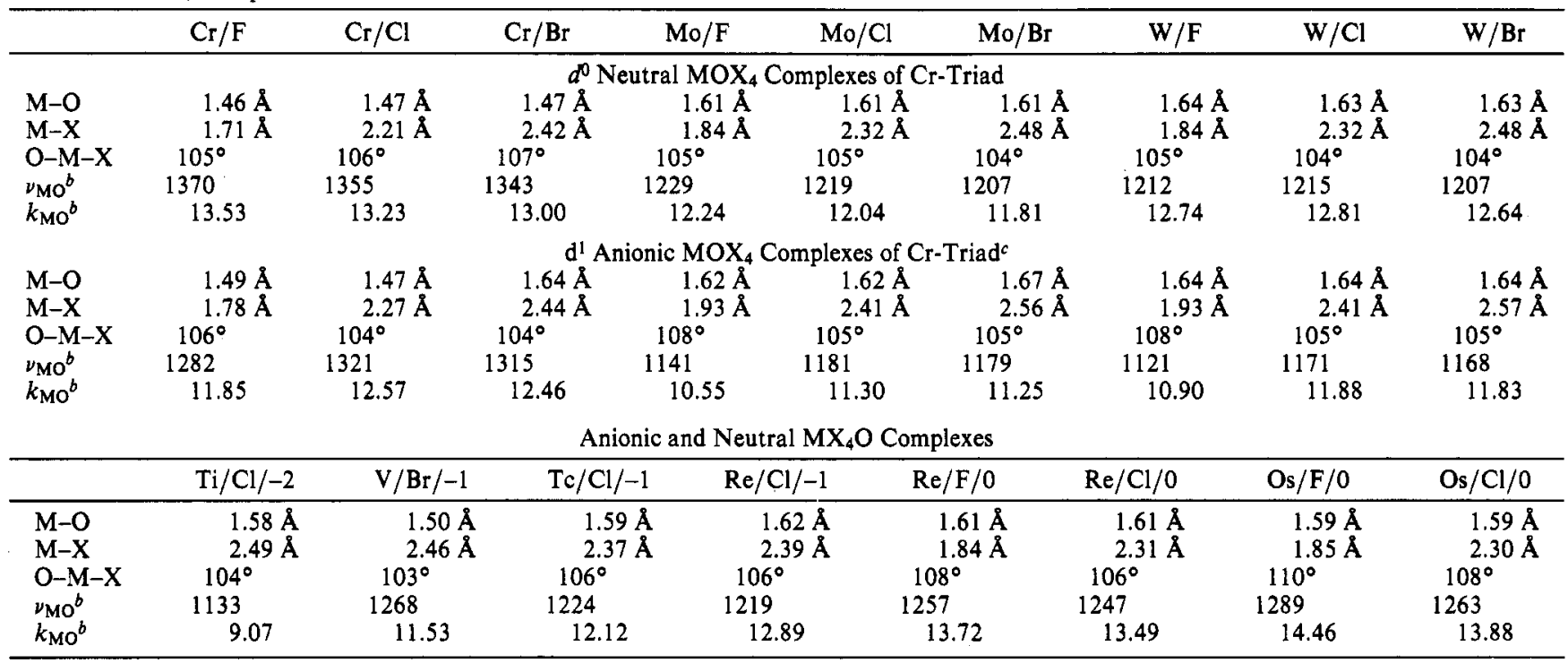

a Column headings are of the form $\mathrm{M} / \mathrm{X} / \mathrm{q} ; \mathrm{M}$ is the transition metal; $\mathrm{X}$ is the halide ligand; $\mathrm{q}$ is the overall charge on the complex. The complexes are all $C_{4 v}$ minima as shown below. ${ }^{b}$ Intrinsic stretching frequencies $\left(\nu_{\mathrm{MCh}}\right.$, in $\left.\mathrm{cm}^{-1}\right)$ and $\mathrm{MCh}$ force constants $\left(k_{\mathrm{MCh}}\right.$, in mdyn $\left.\AA^{-1}\right)$ are calculated using the method of Boatz and Gordon. ${ }^{20}$

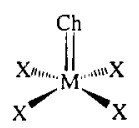

halide bond lengths are too high by a similar small percentage; oxo-metal-halide bond angles are in the range $105 \pm 3^{\circ}$, as are experimental values. For $\mathrm{WOCl}_{4}{ }^{-}$the calculated $\mathrm{WO}$ bond length is $1.64 \AA$ in very good agreement with data ${ }^{48}$ for $\left[\mathrm{WOCl}_{4}\right]^{-}\left[\mathrm{PPh}_{4}\right]^{+}, 1.676(7) \AA$, and only $0.01 \AA$ longer than the calculated WO bond length in $\mathrm{WOCl}_{4}$, Table 3 . The calculated $\mathrm{CrO}$ bond length in the $C_{4 v}$ minimum of $\mathrm{CrOCl}_{4}^{-}$is $1.47 \AA$, in good agreement with the experimental value of $1.519(12) \AA$ for the $\left[\mathrm{AsPh}_{4}\right]^{+}$salt of $\mathrm{CrOCl}_{4}{ }^{-49}$ Note that calculated $\mathrm{CrO}$ bond lengths are essentially identical (and the intrinsic stretching frequency for $\mathrm{CrO}$ bonds shift by only $34 \mathrm{~cm}^{-1}$ ) for the $\mathrm{d}^{0}$ neutral and $\mathrm{d}^{1}$ anion, as expected from the simple bonding model ${ }^{63}$ outlined above for $\mathrm{MOX}_{4}$ complexes, 4. The salts $\left[\mathrm{MOOCl}_{4}\right]^{-}\left[\mathrm{AsPh}_{4}\right]^{+}$ and $\left[\mathrm{MoOBr}_{4}\right]^{-}\left[\mathrm{PPh}_{4}\right]^{+}$have reported $\mathrm{MoO}$ bond lengths of $1.610-$ $(10)^{50}$ and $1.726(14) \AA .{ }^{51}$ Calculated $\mathrm{MoO}$ values are $1.62 \AA$ for both tetra(chloro) and tetra(bromo) analogues. The wide variance in oxo complexes has been well studied in connection with distortional isomerism, and the above examples have been quoted in support of this phenomenon. ${ }^{64}$ Recent computations by Song and Hall ${ }^{65}$ and experiments by Parkin ${ }^{66}$ and Desrochers et al. ${ }^{67}$ have called distortional isomerism into question. We find no evidence for stable, long bond isomers in any five-coordinate, oxyhalides of the Cr-triad.

Several anionic and neutral MOX $_{4}$ complexes have been structurally characterized where $\mathrm{M}$ is not of the $\mathrm{Cr}$-triad. ${ }^{52-55,60-62}$ Ground-state structures are $C_{4 v}$ in computational and experimental models, Table 3. We have previously discussed the good agreement between theory and experiment ${ }^{22}$ for $\mathrm{ReOCl}_{4}^{-}(\mathrm{C})$. The metric data for $\mathrm{VOBr}_{4}^{-}$is $\mathrm{VO}=1.50 \AA(1.552(9) \AA$, experimental), $\mathrm{VBr}=2.46 \AA(2.412(1) \AA$, experimental), and $\mathrm{OVBr}=103^{\circ}\left(103.1(1)^{\circ}\right) . .^{53}$ Note that the calculated $\mathrm{TiO}$ bond length in $\mathrm{TiOCl}_{4}{ }^{2-}$ is $1.58 \AA$, in line with data for other titanyl complexes (vide supra), ${ }^{30-34}$ but significantly shorter than the reported $\mathrm{Ti}-$ oxo bond length in the bis $\left(\mathrm{NEt}_{4}{ }^{+}\right)$salt of $\mathrm{TiOCl}_{4}{ }^{2-} .52$ The cause for the discrepancy among the calculations, $\mathrm{X}$-ray data for other titanyl complexes, ${ }^{30-36}$ and the crystal structure ${ }^{52}$ of $\left[\mathrm{NEt}_{4}\right]_{2}+\left[\mathrm{TiOCl}_{4}\right]^{2-}$ is unclear. Cotton et al. ${ }^{54}$ have characterized the PPN ${ }^{+}$salt of $\mathrm{TcCl}_{4} \mathrm{O}^{-}$which shows good agreement with calculations: $\mathrm{TcO}=1.59 \AA(1.610(4) \AA), \mathrm{TcCl}=2.37 \AA$ $(2.291(1) \AA-2.317(2) \AA$, av $=2.31 \AA)$, and OTcCl $=106^{\circ}(103.0-$ $\left.(2)-111.5(3)^{\circ}, \mathrm{av}=107^{\circ}\right)$. The calculated structure for $\mathrm{OsOCl}_{4}$ has $\mathrm{OsO}=1.59 \AA, \mathrm{OsCl}=2.30 \AA$, and $\mathrm{OOsCl}=108^{\circ}$ in reasonable agreement with gas-phase electron diffraction studies: ${ }^{60} \mathrm{OsO}=1.663(9) \AA, \mathrm{OsCl}=2.358(5) \AA$ and $\mathrm{OOsCl}=108.3$ $(4)^{\circ}$. The complex OsOMe $\mathrm{OM}_{4}$ is a rare case of a stable, high-valent organometallic oxide. ${ }^{62}$ Calculated and experimentally determined (by electron diffraction) metric data show excellent correspondence: $\mathrm{OsO}=1.681(1) \AA(1.64 \AA$, calcd $), \mathrm{OsC}=2.096$ (3) $\AA(2.11 \AA$, calcd $)$, OOsC $=112.2(5)^{\circ}\left(113^{\circ}\right.$, calcd $)$, COsC $=81.8(4)^{\circ}\left(81^{\circ}\right.$, calcd $) .62$

Recent electron diffraction (ED) studies of neutral $\mathrm{MX}_{4} \mathrm{Ch}$ complexes provide another good opportunity to investigate the flexibility of the ECP approach for a series of chalcogens. ${ }^{2.14}$ For $\mathrm{d}^{0}$, group VIB oxos, $\mathrm{MOX}_{4}$, calculated metal-oxo bond lengths for $C_{4 v}$ minima show minimal change as a function of halide ligand: $\mathrm{CrO}=1.46 \AA\left(\mathrm{CrOF}_{4}\right), 1.47 \AA\left(\mathrm{CrOBr}_{4}\right.$ and $\left.\mathrm{CrOBr}_{4}\right)$; $\mathrm{MoO}=1.61 \AA\left(\mathrm{MoOF}_{4}, \mathrm{MoOCl}_{4}\right.$, and $\left.\mathrm{MoOBr}_{4}\right) ; \mathrm{WO}=1.64$ $\AA\left(\mathrm{WOF}_{4}\right)$ and $1.63 \AA\left(\mathrm{WOCl}_{4}\right.$ and $\left.\mathrm{WOBr}_{4}\right)$. Calculated metaloxo bond lengths compare very well with data from electron diffraction: $\mathrm{MoO}=1.650(3) \AA\left(\mathrm{MoOF}_{4}\right),{ }^{57} \mathrm{MoO}=1.658(2)$ $\AA\left(\mathrm{MoOCl}_{4}\right),{ }^{56} \mathrm{WO}=1.666(4) \AA\left(\mathrm{WOF}_{4}\right),{ }^{59} \mathrm{WO}=1.684(4)$ $\AA\left(\mathrm{WOCl}_{4}\right),{ }^{59}$ and $\mathrm{WO}=1.684(3) \AA\left(\mathrm{WOBr}_{4}\right){ }^{59}$ The entire series of complexes $\mathrm{WX}_{4} \mathrm{Ch}$ has been characterized by ED for $\mathrm{X}=\mathrm{F}, \mathrm{Cl}, \mathrm{Br}, \mathrm{Ch}=\mathrm{O}, \mathrm{S}, \mathrm{Se}^{14}$ Calculated and experimental data for these $\mathrm{WX}_{4} \mathrm{Ch}$ complexes are collected in Table 4 along with calculated values for the as yet unsynthesized telluridos. The WCh bond distances in $\mathrm{WCl}_{4} \mathrm{Ch}$, Table 4 , relative to the oxo are WS-WO $=0.44 \AA(0.42 \AA$, experimental); WSe-WO $=0.54 \AA(0.51 \AA$, experimental $)$, and $\mathrm{WTe}-\mathrm{WO}=0.77 \AA$, showing good reproduction of experimental trends. ${ }^{14}$ Differences in bond lengths relative to the oxo analogue are closer to those found for $\mathrm{Cl}_{3} \mathrm{TaCh}$ than $\mathrm{Cp}_{2} \mathrm{ZrCh}$. In terms of absolute predictions there is very good agreement for $\mathrm{MCh}, \mathrm{MX}$, and ChMX metric data; MCh bonds tend to be short by only $2-3 \%$, and $\mathrm{MX}$ bond lengths are long by a few percent on average. Thus, as found for group IVB metallocenes and $\mathrm{Ta}$ there is consistently good agreement between experiment and ECP calculated geometries for a continuous series of chalcogens.

iv. $\mathbf{M}(\mathbf{X})_{\mathbf{5}}(\mathbf{O})$ Complexes. Six-coordinate oxos based on the octahedral geometry have been widely studied. ${ }^{2}$ The $\mathrm{X}_{5}$ ligand set can be anything from a porphyrin ring with an axial ligand to five unidentate halides or a wide variety of neutral Lewis 
Table 4. $\mathrm{WCl}_{4} \mathrm{Ch}$ Complexes

\begin{tabular}{|c|c|c|c|c|c|c|c|c|}
\hline & $\mathrm{MCh}_{\text {calc }}$ & $M \mathrm{Ch}_{\text {expt }}$ & $\mathrm{MX}_{\mathrm{calc}}$ & $\mathrm{MX}_{\text {expt }}$ & $\mathrm{ChMX}_{\text {calc }}$ & $\mathrm{ChMX}_{\text {expt }}$ & $\nu_{\mathrm{MCh}}$ & $k_{\mathrm{MCh}}$ \\
\hline $\mathrm{WF}_{4} \mathrm{O}$ & $1.64 \AA$ & $1.67 \AA$ & $1.84 \AA$ & $1.85 \AA$ & $105^{\circ}$ & $105^{\circ}$ & 1212 & 12.74 \\
\hline $\mathrm{WCl}_{4} \mathrm{O}$ & $1.63 \AA$ & $1.69 \AA$ & $2.32 \AA$ & $2.28 \AA$ & $104^{\circ}$ & $102^{\circ}$ & 1215 & 12.81 \\
\hline $\mathrm{WBr}_{4} \mathrm{O}$ & $1.63 \AA$ & $1.68 \AA$ & $2.48 \AA$ & $2.44 \AA$ & $104^{\circ}$ & $103^{\circ}$ & 1200 & 12.51 \\
\hline $\mathrm{WF}_{4} \mathrm{~S}$ & $2.05 \AA$ & $2.10 \AA$ & $1.84 \AA$ & $1.85 \AA$ & $106^{\circ}$ & $105^{\circ}$ & 625 & 6.26 \\
\hline $\mathrm{WCl}_{4} \mathrm{~S}$ & $2.07 \AA$ & $2.11 \AA$ & $2.32 \AA$ & $2.28 \AA$ & $102^{\circ}$ & $104^{\circ}$ & 638 & 6.53 \\
\hline $\mathrm{WBr}_{4} \mathrm{~S}$ & $2.05 \AA$ & $2.11 \AA$ & $2.48 \AA$ & $2.43 \AA$ & $105^{\circ}$ & $104^{\circ}$ & 632 & 6.40 \\
\hline $\mathrm{WF}_{4} \mathrm{Se}$ & $2.20 \AA$ & $2.23 \AA$ & $1.84 \AA$ & $1.85 \AA$ & $106^{\circ}$ & $105^{\circ}$ & 406 & 5.41 \\
\hline $\mathrm{WCl}_{4} \mathrm{Se}$ & $2.17 \AA$ & $2.20 \AA$ & $2.33 \AA$ & $2.28 \AA$ & $105^{\circ}$ & $104^{\circ}$ & 419 & 5.76 \\
\hline $\mathrm{WBr}_{4} \mathrm{Se}$ & $2.18 \AA$ & $2.22 \AA$ & $2.48 \mathrm{~A}$ & $2.43 \AA$ & $105^{\circ}$ & $103^{\circ}$ & 414 & 5.63 \\
\hline $\mathrm{WF}_{4} \mathrm{Te}$ & $2.40 \AA$ & $\mathbf{N A}^{b}$ & $1.84 \AA$ & NA & $106^{\circ}$ & NA & 289 & 3.75 \\
\hline $\mathrm{WCl}_{4} \mathrm{Te}$ & $2.40 \AA$ & NA & $2.33 \AA$ & NA & $105^{\circ}$ & NA & 309 & 4.29 \\
\hline $\mathrm{WBr}_{4} \mathrm{Te}$ & $2.40 \AA$ & NA & $2.48 \AA$ & NA & $105^{\circ}$ & NA & 305 & 4.19 \\
\hline
\end{tabular}

${ }^{a}$ Experimental data for these complexes are taken from ref 14 ; all complexes are $C_{4 v}$ minima. ${ }^{b} \mathrm{NA}=$ not available.

Table 5. $\mathrm{MOX}_{5}$ Complexes $^{a}$

\begin{tabular}{|c|c|c|c|c|c|c|c|c|c|c|}
\hline & $V / F /-2$ & $\mathrm{~V} / \mathrm{Cl} / \mathrm{-2}$ & $\mathrm{Nb} / \mathrm{F} /-2$ & $\mathrm{Nb} / \mathrm{Cl} /-2$ & $\mathrm{Cr} / \mathrm{Cl} /-2$ & $\mathrm{Mo} / \mathrm{F} /-2$ & $\mathrm{Mo} / \mathrm{Cl} /-2$ & $\mathrm{Mo} / \mathrm{Br} /-2$ & $\mathrm{~W} / \mathrm{Cl} /-2$ & $\mathrm{~W} / \mathrm{Br} /-2$ \\
\hline cis & $\begin{array}{l}1.55 \AA \\
1.85 \AA \\
1.98 \AA\end{array}$ & & & & & & & & & \\
\hline $\mathrm{O}-\mathrm{M}-\mathrm{X}_{\mathrm{eis}}$ & $95^{\circ}$ & $94^{\circ}$ & $94^{\circ}$ & $94^{\circ}$ & $93^{\circ}$ & $95^{\circ}$ & $93^{\circ}$ & $93^{\circ}$ & $94^{\circ}$ & $93^{\circ}$ \\
\hline$\nu_{\mathrm{MO}}{ }^{b}$ & $\begin{array}{l}1148 \\
9,46\end{array}$ & $\begin{array}{l}1237 \\
10.98\end{array}$ & $\begin{array}{l}990 \\
7.8\end{array}$ & $\begin{array}{c}1089 \\
9.5\end{array}$ & 1283 & 1067 & 1149 & 1155 & 1143 & 1149 \\
\hline
\end{tabular}

a Column headings are of the form $\mathrm{M} / \mathrm{X} / \mathrm{q} ; \mathrm{M}$ is the transition metal; $\mathrm{X}$ is the halide ligand; $\mathrm{q}$ is the overall charge on the complex. The complexes are all $C_{4 v}$ minima as shown below. Group VIB complexes have a ${ }^{2} \mathrm{~B}_{2}$ ground state and were calculated using a restricted open-shell Hartree-Fock (ROHF) wave function. ${ }^{b}$ Intrinsic stretching frequencies $\left(\nu_{\mathrm{MCh}}\right.$, in $\left.\mathrm{cm}^{-1}\right)$ and $\mathrm{MCh}$ force constants $\left(k_{\mathrm{MCh}}\right.$, in mdyn $\left.\AA^{-1}\right)$ are calculated using the method of Boatz and Gordon. ${ }^{20}$

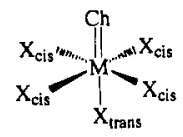

bases. ${ }^{2-4}$ The interesting story of distortional isomerism has lead to interest in the $\mathrm{MX}_{5} \mathrm{O}$ motif. ${ }^{64-67}$ Below we consider a small sample of $C_{4 v} \mathrm{MX}_{5} \mathrm{O}$ complexes for which vibrational data has been published. ${ }^{2-4}$ The prevalence of $d$ orbital occupancies of 0 , 1 , and 2 in $\mathrm{MX}_{5} \mathrm{O}$ complexes is explained by the classic Ballhausen-Gray analysis ${ }^{63}$ which is very similar to the bonding picture given in 4. Two orbitals in the $t_{2 \mathrm{~g}}$ set of octahedral complexes are perturbed to higher energy by the $\pi$-donor ability of the oxo, leaving a low-energy, nonbonding $d$ orbital $\left(d_{x y}\right.$ if the MO vector is the $z$-axis) which can hold either 0,1 , or 2 electrons. Complexes with $d$ populations greater than 2 must populate orbitals which are metal $\mathrm{d} \pi-\mathrm{O} \mathrm{p} \pi$ antibonding, thus contributing to instability of the complex. The few examples of $\mathrm{MX}_{5} \mathrm{O}$ complexes with $d$ orbital occupancies of greater than 2 such as Meyer's d $d^{4}-\mathrm{Ru}(\mathrm{IV})$-oxo polypyridyl ${ }^{68}$ and the putative $\mathrm{Fe}(\mathrm{V})$ oxo active species in cytochrome $\mathrm{P}-450^{7}$ are highly reactive intermediates.

The $\mathrm{MOX}_{5}$ complexes in Table 5 are $C_{4 v}$ minima. As expected, addition of a halide trans to the oxo lengthens the metal-oxo bond in $\mathrm{MOX}_{5}$, Table 5, versus that in $\mathrm{MOX}_{4}$ for Cr-triad metals,

(63) Ballhausen, C. J.; Gray, H. B. Inorg. Chem. 1962, 1, 111.

(64) Other examples purporting to show distortional isomerism are collected in Table 5.1 of ref $2, \mathrm{p} 153$. A statistical analysis of reported metal $-0 x 0$ bond lengths, and the relation of metal-oxo bond lengths in "bond stretched isomers" to the majority of $\mathrm{L}_{n} \mathrm{MO}$ complexes is given: Mayer, J. M. Inorg. Chem. 1988, 27, 3899

(65) Song, J.; Hall, M. B. J. Am. Chem. Soc. 1991, 30, 4433

(66) (a) Parkin, G. Acc. Chem. Res. 1992, 25, 455. (b) Parkin, G. Chem Rev. 1993, 93, 887.

(67) (a) Desrochers, P. J.; Nebesny, K. W.; LaBarre, M. J.; Lincoln, S E.; Loehr, T. M.; Enemark, J. H. J. Am. Chem. Soc. 1991, 113, 9193. (b) Desrochers, P. J.; Nebesny, K. W.; LaBarre, M. J.; Bruck, M. A.; Neilson G. F.; Sperline, R. P.; Enemark, J. H.; Backes, G.; Wieghardt, K. Inorg. Chem. 1994, 33, 15.

(68) (a) Dobson, J. C.; Seon, S. K.; Meyer, T. J. Inorg. Chem. 1986, 25 , 1513. (b) Roecker, L.; Meyer, T. J. J. Am. Chem. Soc. 1987, 109, 746. (c) Roeker, L.; Dobson, J. C.; Vining, W. J.; Meyer, T. J. Inorg. Chem. 1987 26, 779. (d) Thompson, M. S.; Meyer, T. J. J. Am. Chem. Soc, 1982, 104 4106. (c) Dobson, J. C.; Helms, J. H.; Doppelt, P.; Sullivan, B. P.; Hatfield, W. E.; Meyer, T. J.Inorg. Chem. 1989, 28, 2200. (f) Sullivan, B. P.; Lumpkin, R. S.; Meyer, T. T. Inorg. Chem. 1987, 26, 1247.
Table 3. The $\mathrm{d}^{1} \mathrm{MOX}_{5}$ complexes have a ${ }^{2} \mathrm{~B}_{2}$ ground state. ${ }^{63} \mathrm{~A}$ comparison between calculated and experimental $\mathrm{ReOF}_{5}$ structures is given elsewhere. ${ }^{22}$ Calculated metal-oxo bond lengths in $\mathrm{VF}_{5} \mathrm{O}^{2-}$ and $\mathrm{VCl}_{5} \mathrm{O}^{2-}$ are 1.55 and $1.51 \AA$, respectively, in very good agreement with VO $=1.54(1) \AA$ in $\left[\mathrm{VF}_{5} \mathrm{O}\right]^{2-}\left[\mathrm{enH}_{2}\right]^{+}{ }_{2}{ }^{69}$ The $\mathrm{VF}_{\mathrm{cis}}$ bond lengths of $1.85 \AA$ concur with average crystal structure values $\left(\mathrm{VF}_{\mathrm{cis}}=1.80 \AA\right) ; 69$ the calculated $\mathrm{VF}_{\text {trans }}$ bond is $1.98 \AA$, longer than $\mathrm{VF}_{\text {cis }}$, but $0.12 \AA(6 \%)$ shorter than $\mathrm{VF}_{\text {trans }}$ in $\left[\mathrm{VF}_{5} \mathrm{O}\right]^{2-}\left[\mathrm{enH}_{2}\right]^{+}{ }_{2}{ }^{69}$ The salt $\mathrm{K}_{2} \mathrm{MoOF}_{5} \cdot \mathrm{H}_{2} \mathrm{O}$ has been characterized: ${ }^{70} \mathrm{MoO}=1.66(2) \AA(1.68 \AA$, calcd $), \mathrm{MoF}_{\text {cis }}(\mathrm{av})$ $=1.88 \AA(1.99 \AA$, calcd $), \mathrm{MoF}_{\text {trans }}=2.03 \AA$ (2.05 $\AA$, calcd $)$, $\mathrm{OMoF}_{\text {cis }}$ (av) $=94^{\circ}\left(95\right.$, calcd). The complex $\mathrm{NbF}_{5} \mathrm{O}^{2-}$ has an $\mathrm{NbO}$ bond length of $1.73 \AA$, in good agreement with the crystallographically determined value of $1.75(2) \AA .{ }^{70}$ Interestingly, the closely related complex $\mathrm{NbCl}_{5} \mathrm{O}^{2-}$ has a calculated $\mathrm{NbO}$ bond length which is shorter than the pentafluoro analogue (a similar trend to that found in the previous $\mathrm{V}^{+5}$ complexes), while the crystal structure ${ }^{71}$ of $\left[\mathrm{NbCl}_{5} \mathrm{O}\right]^{2-}\left[\mathrm{AsPh}_{4}\right]^{+}{ }_{2}$ puts the $\mathrm{NbO}$ bond length in $\left[\mathrm{NbF}_{5} \mathrm{O}\right]^{2-}\left[\mathrm{N}_{2} \mathrm{H}_{6}\right]^{2+}$ at $1.967(6) \AA^{70}$ or roughly $0.2 \AA$ longer than the NbO bond in pentafluoro dianion! It is uncertain to what extent these differences are due to distortional isomerism ${ }^{64-67}$ and to what extent this is a reflection of differences in the trans influence of halides.

b. $\mathbf{L}_{n} \mathbf{M}(\mathbf{C h})_{2}$. Dioxo complexes and heavier analogues are general four or six coordinate. ${ }^{2}$ Dichalcogenido complexes have been reported for the $\mathrm{V}$-, $\mathrm{Cr}$-, $\mathrm{Mn}$-, and $\mathrm{Fe}$-triads. In $\mathrm{MX}_{2} \mathrm{Ch}_{2}$ the metal is typically from the Cr-triad, although $\mathrm{d}^{1} \operatorname{Re}(\mathrm{O})_{2}-$ (Mes) ${ }_{2}{ }^{72} \mathrm{~d}^{2} \mathrm{Os}(\mathrm{O})_{2}$ (Mes) ${ }_{2},{ }^{72}$ and $\mathrm{d}^{0} \mathrm{Os}(\mathrm{O})_{2}(\mathrm{~N}-\mathrm{t}-\mathrm{Bu})_{2}{ }^{73}$ have been reported. Dioxo complexes have seen much interest in connection with their ability to oxidize organic substrates, using $\mathrm{O}_{2}$ as an

(69) Rieskamp, H.; Mattes, R, Z Naturforsch, 1976, $31 B, 1453$

(70) Gorbunov, Y. E.; Pakhomov, V. I.; Kuznetsov, V. G.; Kovaleva, E. S. Zh. Strukt. Khim. 1972, 13, 165 quoted in ref 2, p 192.

(71) Müller, V. U.; Lorenz, I. Z. Anog. Allg. Chem. 1980, 463, 110.

(72) Stavropoulos, P.; Edwrads, P.G.; Behling, T.; Wilkinson, G.; Motevalli, M.; Hursthouse, M. B. J. Chem. Soc., Dalton Trans. 1987, 169.

(73) Nugent, W. A.; Harlow, R. L.; McKinney, R. J. J. Am. Chem. Soc. $1979,101,7265$. 
Table 6. $\mathrm{M}(\mathrm{O})_{2}(\mathrm{X})_{2}$ Complexes $^{a}$

\begin{tabular}{|c|c|c|c|c|c|c|c|c|c|}
\hline & $\mathrm{Cr} / \mathrm{F}$ & $\mathrm{Cr} / \mathrm{Cl}$ & $\mathrm{Cr} / \mathrm{Br}$ & Mo/F & $\mathrm{Mo} / \mathrm{Cl}$ & $\mathrm{Mo} / \mathrm{Br}$ & $\mathrm{W} / \mathrm{F}$ & $\mathrm{W} / \mathrm{Cl}$ & $\mathrm{W} / \mathrm{Br}$ \\
\hline $\begin{array}{l}\mathrm{M}-\mathrm{O} \\
\mathrm{M}-\mathrm{X} \\
\mathrm{O}-\mathrm{M}-\mathrm{O} \\
\mathrm{X}-\mathrm{M}-\mathrm{X} \\
\nu_{\mathrm{Mo}}{ }^{b} \\
k_{\mathrm{MO}}{ }^{b}\end{array}$ & $\begin{array}{c}1.50 \AA \\
1.70 \AA \\
109^{\circ} \\
109^{\circ} \\
1261 \\
11.46\end{array}$ & $\begin{array}{c}1.50 \AA \\
2.12 \AA \\
109^{\circ} \\
111^{\circ} \\
1238 \\
11.04\end{array}$ & $\begin{array}{c}1.50 \AA \\
2.28 \AA \\
110^{\circ} \\
111^{\circ} \\
1223 \\
10.78\end{array}$ & $\begin{array}{c}1.65 \AA \\
1.85 \AA \\
107^{\circ} \\
110^{\circ} \\
1149 \\
10.69\end{array}$ & $\begin{array}{c}1.64 \AA \\
2.29 \AA \\
107^{\circ} \\
111^{\circ} \\
1138 \\
10.49\end{array}$ & $\begin{array}{c}1.64 \AA \\
2.43 \AA \\
107^{\circ} \\
112^{\circ} \\
1131 \\
10.36\end{array}$ & $\begin{array}{c}1.67 \AA \\
1.84 \AA \\
108^{\circ} \\
111^{\circ} \\
1142 \\
11.30\end{array}$ & $\begin{array}{c}1.66 \AA \\
2.29 \AA \\
107^{\circ} \\
113^{\circ} \\
1140 \\
11.27\end{array}$ & $\begin{array}{c}1.66 \AA \\
2.43 \AA \\
107^{\circ} \\
113^{\circ} \\
1134 \\
11.14\end{array}$ \\
\hline \multicolumn{10}{|c|}{$\mathrm{W}(\mathrm{Ch})\left(\mathrm{Ch}^{\prime}\right)(\mathrm{Cl})_{2}$ Complexes $^{c}$} \\
\hline & & $0 / 0$ & $\mathrm{O} / \mathrm{s}$ & & $\mathrm{O} / \mathrm{Se}$ & $\mathrm{S} / \mathrm{S}$ & \multicolumn{2}{|c|}{$\mathrm{S} / \mathrm{Se}$} & $\mathrm{Se} / \mathrm{Se}$ \\
\hline $\begin{array}{l}\mathrm{W}-\mathrm{Ch} \\
\mathrm{W}-\mathrm{Ch}^{\prime} \\
\mathrm{Ch}-\mathrm{W}-\mathrm{C} \\
\nu_{\mathrm{MCh}}{ }^{b} \\
k_{\mathrm{MCh}}{ }^{b} \\
\nu_{\mathrm{MCb}^{b}} \\
k_{\mathrm{MCb}}{ }^{b}\end{array}$ & & $\begin{array}{c}1.66 \AA \\
2.29 \AA \\
107^{\circ} \\
1140 \\
11.27\end{array}$ & $\begin{array}{c}1.65 \AA \\
2.11 \AA \\
108^{\circ} \\
1160 \\
11.66 \\
586 \\
5.52\end{array}$ & & $\begin{array}{c}1.65 \AA \\
2.23 \AA \\
108^{\circ} \\
1161 \\
11.68 \\
379 \\
4.72\end{array}$ & $\begin{array}{c}2.09 \AA \\
2.09 \AA \\
109^{\circ} \\
593 \\
5.65\end{array}$ & $\begin{array}{r}2 . \\
2 . \\
109 \\
597 \\
5 . \\
386 \\
4 .\end{array}$ & & $\begin{array}{c}2.21 \AA \\
2.21 \AA \\
110^{\circ} \\
386 \\
4.90\end{array}$ \\
\hline
\end{tabular}

${ }^{a}$ Complexes of the type $\mathrm{M}(\mathrm{X})_{2}(\mathrm{Ch})\left(\mathrm{Ch}^{\prime}\right)$ are $C_{2 y}\left(\mathrm{Ch}=\mathrm{Ch}^{\prime}\right)$ and $C_{s}\left(\mathrm{Ch} \neq \mathrm{Ch}^{\prime}\right)$ minima as shown below. ${ }^{b}$ Intrinsic stretching frequencies $\left(\nu_{\mathrm{MCh}}\right.$, in $\left.\mathrm{cm}^{-1}\right)$ and MCh force constants $\left(k_{\mathrm{MCh}}\right.$, in mdyn $\left.\mathrm{A}^{-1}\right)$ are calculated using the method of Boatz and Gordon. ${ }^{20} \mathrm{c}$ For cases in which $\mathrm{Ch} \neq \mathrm{Ch}^{\prime}, \mathrm{Ch}$ is the lighter chalcogenide.

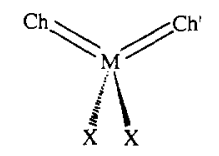

oxygen source. ${ }^{74-76}$ trans-Dichalcogenido W(IV) complexes $\left(\mathrm{W}(\mathrm{L})_{4}(\mathrm{Ch})_{2}, \mathrm{~L}=\right.$ neutral ligand $\left(\mathrm{PMe}_{3}\right.$ or isocyanide) $)$ have been synthesized for $(\mathrm{Ch})_{2}=(\mathrm{S})_{2},{ }^{77}(\mathrm{Se})_{2},{ }^{78}(\mathrm{Te})_{2},{ }^{11}(\mathrm{~S})(\mathrm{Se}),{ }^{78}$ and $(\mathrm{Se})(\mathrm{Te}),{ }^{78}$ with mixed chalcogenidos as not yet structurally characterized. A mixed bis(chalcogenido) complex $\mathrm{Mo}^{\mathrm{IV}}$ (dppe) $2_{2}^{-}$ (O)(S) has been reported. ${ }^{79}$ The general preference of $\mathrm{d}^{0}$ and $\mathrm{d}^{2}$ $\mathrm{L}_{4} \mathrm{M}(\mathrm{Ch})_{2}$ complexes for cis and trans, respectively, arrangements of the chalcogenides has been explained in terms of less competition among the $\mathrm{p} \pi$ orbitals of the Ch ligands for vacant $\mathrm{d} \pi$ orbitals in the former and the presence of a metal nonbonding orbital to accept the two $d$ electrons in the latter. ${ }^{4}$

$\mathbf{M C h}_{2} \mathrm{X}_{2}$ Complexes. Calculated $\mathrm{MX}_{2} \mathrm{O}_{2}$ minima are $C_{2 v}{ }^{2}$ The calculated minimum in chromyl chloride has $\mathrm{CrO}=1.50 \AA$ (1.57(3), experimental), $\mathrm{CrCl}=2.12 \AA(2.12(3) \AA), \mathrm{OCrO}=109^{\circ}$ $\left(105(4)^{\circ}\right)$, and $\mathrm{ClCrCl}=109^{\circ}\left(113(3)^{\circ}\right),{ }^{37}$ Table 6. $\mathrm{Cr}(\mathrm{O})_{2-}$ $\left(\mathrm{OC}_{15} \mathrm{H}_{25}\right)_{2}$ has reported $\mathrm{Cr}-0 \times 0$ bond lengths of 1.57 (1) $\AA$ and an oxo- $\mathrm{Cr}$-oxo bond angle of $107.2(8)^{0,80}$ the bond length is clearly closer to electron diffraction results. ${ }^{37}$ The complex $\mathrm{Cr}$ (O) ${ }_{2}\left(\mathrm{OSiPh}_{3}\right)_{2}$ shows two inequivalent $\mathrm{Cr}$-oxo bonds: (1.514(13) $\AA$ (closer to the calculated value) and $1.568(12) \AA$ (closer to the ED result). ${ }^{81}$ Fortunately, a more recent ED study of chromyl chloride has been published; ${ }^{82}$ newer data are consistent with $\mathrm{Palmer}^{37}$ except that $\mathrm{OCrO}$ is larger in the newer study $\left(108.5(4)^{\circ}\right)$, hence closer to the calculated value, Table 6 . French et al. ${ }^{83}$ have reported an ED study of $\mathrm{CrO}_{2} \mathrm{~F}_{2}$ and here again the calculated $\mathrm{CrO}$ bond length is $1.50 \AA, 5 \%$ shorter than experiment $(1.575(2) \AA)$, while other calculated metric data are in excellent agreement with experiment. Based on studies of TM multiple bonding ${ }^{15}$ it is found that for a given family of compounds the importance of electron correlation increases as one goes from right to left in the transition series and from heavier to lighter members of a triad. 21 .

(74) Goldstein, A. S.; Drago, R. S. J. Chem. Soc., Chem. Comm. 1991,

(75) (a) Groves, J. T.; A hn, K. H. Inorg. Chem. 1987, 26, 3831. (b) Groves, J. T.; Quinn, R.J. Am. Chem. Soc. 1985, 107, 5790. (c) Groves, J. T.; Quinn, R. Inorg. Chem. 1984, 23, 3844.

(76) Bailey, C. L.; Drago, R. S. J. Chem. Soc., Chem. Commun. 1987, 179.

(77) Rabinovich, D.; Parkin, G. J. Am. Chem. Soc. 1991, 113, 5904.

(78) Parkin, G. Chemistry, Columbia, Personal communication.

(79) Lorenz, I. P.: Walter, G.; Hiller, W. Chem. Ber. 1990, 123, 979.

(80) Amirthalingham, V.; Grant, V. F.; Senol, A. Acta Crystallogr. 1972, $B 28,1340$.

(81) Stensland, B.; Kierkegaard, P. Acta Chem. Scand. 1970, 24, 211. (82) Marsden, C. J.; Hedberg, L.; Hedberg, K. Inorg. Chem. 1982, 21 , 1115.

(83) French, R. J.; Hedberg, L.; Hedberg, K.; Gard, G. L.; Johnson, B. M. Inorg. Chem. 1983, 22, 892.
Metal-oxo bond lengths in molybdenyl and tungstenyl halides are roughly $0.03-0.05 \AA$ shorter $(\approx 2-3 \%)$ than found in complexes in which two additional neutral bases have been coordinated. For example, $\mathrm{Mo}$ and $\mathrm{W}(\mathrm{O})_{2}(\mathrm{Cl})_{2}\left(\mathrm{OPPh}_{3}\right)_{2}$ have metal-oxo bond lengths of $1.673(1) \AA, 1.695(1) \AA(\mathrm{Mo})$ and $1.702(9) \AA, 1.706$ (8) $\AA(W),{ }^{2}$ compared to $\mathrm{MoO}_{\text {caled }}=1.64 \AA$ for $\mathrm{MoO}_{2} \mathrm{Cl}_{2}$ and $\mathrm{WO}_{\text {caled }}=1.66 \AA$ for $\mathrm{WO}_{2} \mathrm{Cl}_{2}$, Table 6. Computations and experiments ${ }^{80-83}$ show near tetrahedral angles about the TM for the $\mathrm{d}^{0}$ group VIB complexes, Table 6.

Research from the Wilkinson lab $b^{72}$ has produced an interesting pair of dioxos: $d^{1} \operatorname{Re}(\mathrm{O})_{2}(\mathrm{Mes})_{2}$ and $\mathrm{d}^{2} \mathrm{Os}(\mathrm{O})_{2}$ (Mes) $)_{2}$. Angles about the TM in Os $(\mathrm{O})_{2}$ (Mes) ${ }_{2}$ deviate markedly from tetrahedral values $;{ }^{72}$ the $\mathrm{O}-\mathrm{Os}-\mathrm{O}$ angle is significantly expanded to 136.1 $(3)^{\circ}$, while the $\mathrm{C}-\mathrm{Os}-\mathrm{C}$ angle is markedly compressed (96.0$\left.(3)^{\circ}\right)$ despite the bulk of the mesityls. ${ }^{72}$ Simple $\mathrm{MO}_{2} \mathrm{Cl}_{2}$ models were investigated with ECP methods. For the series of $\mathrm{MO}_{2} \mathrm{Cl}_{2}$ complexes ( $\mathrm{M}=\mathrm{W}, \mathrm{Re}, \mathrm{Os})$ metal-oxo and metal-chloro bond lengths stay nearly constant at 1.66 and $2.29 \AA$, respectively, consistent with structural data for $d^{1} \operatorname{Re}$ and $d^{2} \mathrm{Os}(\mathrm{O})_{2}$ (Mes) $)_{2}$, i.e., $\mathrm{M}-\mathrm{O}$ and $\mathrm{M}-\mathrm{C}$ bond lengths are roughly equivalent at 1.69 and $2.05 \AA$, respectively. ${ }^{72}$ Calculated oxo-metal-oxo bond angles reproduce the experimental trend of increasing $O M O$ angle with increasing $\mathrm{d}$ orbital occupation: $\mathrm{OMO}=107^{\circ}(\mathrm{W}), 117^{\circ}(\mathrm{Re}$, $121.5(4)^{\circ}$, experimental) and $127^{\circ}\left(136.1(3)^{\circ}\right) .^{72}$ Likewise, the $\mathrm{Cl}-\mathrm{M}-\mathrm{Cl}$ angles decrease in a similar manner to the $\mathrm{C}-\mathrm{M}-\mathrm{C}$ bonds in $\mathrm{MO}_{2} \mathrm{Mes}_{2}: \mathrm{Cl}-\mathrm{M}-\mathrm{Cl}=113^{\circ}(\mathrm{W}), 98^{\circ}(\mathrm{Re})$, and $91^{\circ}$ (Os). Keeping $\mathrm{MO}$ and $\mathrm{MCl}$ bond lengths equal and distorting to tetrahedral angles requires only $2-3 \mathrm{kcal} \mathrm{mol}^{-1}$ at the RHF level for the $\mathrm{Re}^{\mathrm{VI}}$ and $\mathrm{Os}^{\mathrm{VI}}$ complexes. That the observed geometric distortions are reproduced in simple model calculations is consistent with a subtle electronic effect giving rise to angular distortions, and further evidence that ECP methods are adequately describing the electronic structure of these complexes.

Gibson et al..$^{84}$ have developed synthetic routes to $\mathrm{MX}_{2} \mathrm{Ch}_{2}$ complexes for $\mathrm{Ch}=\mathrm{S}$, including mixed chalcogenides such as $\mathrm{Mo}(\mathrm{O})(\mathrm{S}) \mathrm{Cl}_{2}{ }^{84}$ The bis(sulfido) and sulfido(oxo) complexes of $\mathrm{MoCl}_{2}$ and $\mathrm{WCl}_{2}$ have been synthesized, although no metric data has been reported. ${ }^{84}$ We have chosen examples for the metal W $\left(\mathrm{WCl}_{2} \mathrm{Ch}\left(\mathrm{Ch}^{\prime}\right) \mathrm{Ch}, \mathrm{Ch}^{\prime}=\mathrm{O}, \mathrm{S}, \mathrm{Se}\right)$ in order to probe the consequences of competition for $\mathrm{d} \pi-\mathrm{p} \pi$ bonding between cischalcogenido ligands, Table 6 . As expected, there is a weakening of WS and WSe bonds when the strongly $\pi$-bonding oxo ligand

(84) (a) Gibson, V. C.; Shaw, A.; Williams, D. N. Polyhedron 1989, 8 549. (b) Gibson, V. C.; Shaw, A.; Kee, T. P. Polyhedron 1990, 9, 2293. 
Table 7. $\mathrm{XMO}_{3}$ Complexes $^{a}$

\begin{tabular}{lcccccccccc}
\hline & $\mathrm{CrO}_{3} \mathrm{Cl}^{-}$ & $\mathrm{CrO}_{3} \mathrm{~F}^{-}$ & $\mathrm{MoO}_{3} \mathrm{Cl}^{-}$ & $\mathrm{MnO}_{3} \mathrm{~F}$ & $\mathrm{TcO}_{3} \mathrm{~F}$ & $\mathrm{ReO}_{3} \mathrm{Me}$ & $\mathrm{ReO}_{3} \mathrm{~F}$ & $\mathrm{ReO}_{3} \mathrm{Cl}$ & $\mathrm{ReO} \mathrm{Br}_{3} \mathrm{OsO}_{3} \mathrm{~N}^{-}$ \\
\hline $\mathrm{M}-\mathrm{O}$ & $1.55 \AA$ & $1.55 \AA$ & $2.40 \AA$ & $1.51 \AA$ & $1.64 \AA$ & $1.67 \AA$ & $1.66 \AA$ & $1.66 \AA$ & $1.66 \AA$ & $1.73 \AA$ \\
$\mathrm{M}-\mathrm{X}$ & $2.25 \AA$ & $1.78 \AA$ & $1.70 \AA$ & $1.72 \AA$ & $1.84 \AA$ & $2.12 \AA$ & $1.84 \AA$ & $2.28 \AA$ & $2.42 \AA$ & $1.63 \AA$ \\
$\mathrm{O}-\mathrm{M}-\mathrm{X}$ & $107^{\circ}$ & $108^{\circ}$ & $108^{\circ}$ & $106^{\circ}$ & $108^{\circ}$ & $103^{\circ}$ & $109^{\circ}$ & $108^{\circ}$ & $108^{\circ}$ & $108^{\circ}$ \\
$\nu_{\mathrm{MO}}{ }^{b}$ & 1125 & 1113 & 1023 & 997 & 1127 & 1112 & 1142 & 1134 & 1131 & 944 \\
$k_{\mathrm{MO}}{ }^{b}$ & 9.12 & 8.92 & 8.47 & 7.26 & 10.28 & 10.73 & 11.31 & 11.17 & 11.1 & 7.75 \\
\hline
\end{tabular}

${ }^{a}$ All complexes are $\mathrm{d}^{0} C_{3 v}$ minima as shown below. ${ }^{b}$ Intrinsic stretching frequencies $\left(\nu_{\mathrm{MCh}}\right.$, in cm$\left.{ }^{-1}\right)$ and $\mathrm{MCh}$ force constants $\left(k_{\mathrm{MCh}}\right.$, in mdyn $\left.\AA^{-1}\right)$ are calculated using the method of Boatz and Gordon. ${ }^{20}$<smiles>[X][W]([O-])([O-])O</smiles>

is introduced. For example, WSe bond lengths in $\mathrm{WCl}_{2} \mathrm{Se}_{2}$ are $2.21 \AA$ with a force constant of $4.90 \mathrm{mdyn}^{-1} \AA^{-1}$; replacement of selenido (which is expected to be the weakest $\pi$-bonding ligand in the set) with oxo causes the WSe bond to stretch by $0.02 \AA$, and the force constant is reduced to $4.72 \mathrm{mdyn}^{-1}$ (corresponding to $7 \mathrm{~cm}^{-1}$ change in the intrinsic stretching frequency). However, these changes are very small suggesting that competition between $\mathrm{Ch}$ and $\mathrm{Ch}^{\prime}$ bonds for metal $\mathrm{d} \pi$-ligand $\mathrm{p} \pi$ bonding in these pseudotetrahedral complexes is very small.

Geometries for $D_{2 d}$ minima of $\mathrm{W}(\mathrm{Ch})_{2}\left(\mathrm{PH}_{3}\right)_{4}$ models $(\mathrm{Ch}=$ $\mathrm{O}, \mathrm{S}, \mathrm{Se}, \mathrm{Te}$ ) were optimized with ECP methods on parallel supercomputers to compare with recent data ${ }^{11,77,78}$ and to study the trans-bis(chalcogenides) arrangement. A model of the first structurally characterized terminal tellurido, $\mathrm{W}(\mathrm{Te})_{2}\left(\mathrm{PH}_{3}\right)_{4} 5$, shows excellent agreement with experiment for $\mathrm{W}(\mathrm{Te})_{2}\left(\mathrm{PMe}_{3}\right)_{4},{ }^{11}$ in

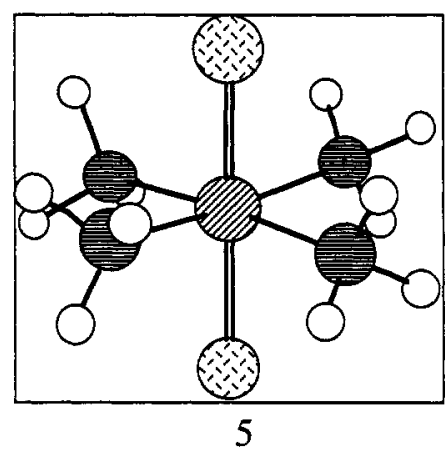

particular for the WTe $e_{2}$ core: ${ }^{11} \mathrm{WTe}=2.61 \AA(2.596(1) \AA)$; WP $=2.57 \AA(2.508(2) \AA) ; \mathrm{TeWTe}=180^{\circ}\left(180^{\circ}\right) ; \mathrm{TeWP}=87^{\circ}$ and $93^{\circ}\left(82.1(1)^{\circ}\right.$ and $\left.97.9(1)^{\circ}\right)$; PWP $=90^{\circ}$ and $175^{\circ}(91.1-$ $(1)^{\circ}$ and $\left.164.2(1)^{\circ}\right)$. The biggest differences are in angles involving the phosphine ligand which is understandable given the difference in the bulk of $\mathrm{PH}_{3}$ model and $\mathrm{PMe}_{3}{ }^{11}$ The bis(selenido) and bis(sulfido) models of 5 have WSe $=2.38$ and WS $=2.26$ $\AA$, in excellent agreement with experiment: $W S e=2.38 \AA^{78}$ and $\mathrm{WS}=2.248(2) .{ }^{77}$ trans-W $\left(\mathrm{PH}_{3}\right)_{4}(\mathrm{O})_{2}$ has a calculated WO bond length of $1.80 \AA$; a bis(oxo) member of the $W^{2} L_{4} \mathrm{Ch}_{2}$ series ( $\mathrm{L}=$ neutral base) has not been reported, but a $\mathrm{d}^{2}$-trans(dioxo) Mo complex, $\mathrm{NaK}_{3}\left[\mathrm{Mo}(\mathrm{O})_{2}(\mathrm{CN})_{4}\right]$, has been characterized. ${ }^{85}$ Analogous bond lengths involving Mo and $\mathrm{W}$ are expected to be similar due to the lanthanide contraction. The trans-dioxo-Mo(IV) complex has $\mathrm{MoO}=1.834$ (9) $\AA$, longer by about $0.1 \AA$ than the typical $\mathrm{MoO}$ bond lengths in $\mathrm{d}^{0}$-cis(dioxo) Mo complexes, in reasonable accord with the calculated value for $\mathrm{W}\left(\mathrm{PH}_{3}\right)_{4}(\mathrm{O})_{2}{ }^{2}$ The mixed sulfido-oxo complex $\mathrm{Mo}(\mathrm{dppe})_{2}(\mathrm{O})(\mathrm{S})$ is of interest for several reasons, not the least of which is the fact that the complex contains an equivalent of sulfuric acid and sulfur dioxide in the unit cell. ${ }^{79}$ An ECP optimization of W(O) $(\mathrm{S})\left(\mathrm{PH}_{3}\right)_{4}$ shows very good agreement with the reported structure: $\mathrm{WO}=1.73$

(85) Day, V. W.; Hoard, J. L. J. Am. Chem. Soc. 1968, 90, 3374.
$\AA\left(\mathrm{MoO}=1.77(1) \AA^{79}\right)$, and $\mathrm{WS}=2.37 \AA(\mathrm{MoS}=2.415(7)$ $\left.\AA^{79}\right)$. Calculations show the WO bond in the sulfido oxo to be shorter than in the trans-dioxo case and the WS bond to be shorter in the trans-bis(sulfido), results pointing to a stronger trans effect for $\mathrm{O}^{2-}$ versus $\mathrm{S}^{2-}$.

c. $\mathbf{L}_{n} \mathbf{M}(\mathbf{C h})_{3}$ Complexes. The trioxo moiety is generally observed to be nonplanar in those complexes in which it appears. ${ }^{4}$ Barium ruthenate, $\mathrm{BaRu}(\mathrm{O})_{3}(\mathrm{OH})_{2}$ is deviant from the norm possessing a planar trioxo moiety in the equatorial plane of a trigonal bipyramid. ${ }^{4}$ Herrmann et al. have recently developed the chemistry of the $\mathrm{ReO}_{3}$ functionality; ${ }^{86}$ applications such as olefin metathesis ${ }^{86 \mathrm{a}}$ and epoxidation ${ }^{86 \mathrm{~b}}$ catalysts have been reported. $\mathrm{X}$ is typically unidentate although $\mathrm{Cp}^{\prime} \mathrm{ReO}_{3}$ has been structurally characterized. ${ }^{87}$ Oxo-bridged species such as dichromate $\left(\mathrm{Cr}_{2} \mathrm{O}_{7}{ }^{2-}\right),{ }^{88}$ dimolybdate $\left(\mathrm{Mo}_{2} \mathrm{O}_{7}{ }^{2-}\right),{ }^{89}$ and $\mathrm{Re}_{2} \mathrm{O}_{7}{ }^{90}$ can also be considered as trioxo complexes. Trichalcogenido moieties for the heavier chalcogens are rare. Examples of which we are aware are $\left[\mathrm{CpTa}(\mathrm{S})_{3}\right]^{2-}$ (terminal sulfidos interact strongly with solvated $\left.\mathrm{Li}^{+}\right)^{91}\left[\mathrm{CpW}(\mathrm{S})_{3}\right]^{-, 92}$ and $\mathrm{MeCp}(\mathrm{dppe}) \operatorname{RuSRe}(\mathrm{S})_{3}{ }^{93}$

The structures of $\mathrm{ReO}_{3} \mathrm{~F}, \mathrm{ReO}_{3} \mathrm{Cl}$, and $\mathrm{MnO}_{3} \mathrm{~F}$ have been studied by microwave spectroscopy. ${ }^{94}$ As expected, there is greater discrepancy between experiment and the RHF geometry (in parentheses) for the complex involving a first-row TM: $\mathrm{MnO}=$ $1.586(5) \AA(1.51 \AA), \mathrm{MnF}=1.724(5) \AA(1.72 \AA)$, and $\mathrm{OMnF}$ $=108.5(1)^{\circ}\left(106^{\circ}\right)$, suggesting that for highly accurate work an account of electron correlation may be desirable for $\mathrm{MnO}_{3} \mathrm{~F}$. The ReO bond lengths are $1.692(3)$ and $1.702(3) \AA$ for the fluoro and chloro complexes, ${ }^{94}$ respectively, in very good agreement with calculated values of $1.66 \AA$, Table 7 . Likewise, calculated and experimental $\mathrm{Re}$-halide and oxo-Re-halide angles show close correspondence: $\operatorname{ReF}=1.859(8) \AA$ (1.84 $\AA$, calcd $), \operatorname{ReCl}=$ 2.229 (4) $\AA$ (2.28 $\AA$, calcd), OReF $=109.5(3)^{\circ}\left(109^{\circ}\right.$, calcd $)$, and $\mathrm{OReCl}=109.3(1)^{\circ}\left(108^{\circ}\right.$, calcd $) .{ }^{94}$ The Cs salt of $\mathrm{OsO}_{3} \mathrm{~N}^{-}$ possesses $O s O$ bond lengths of $\approx 1.74 \AA$ and an $O s N$ bond length of $1.676(15) \AA$, in agreement with calculation $\mathrm{OsO}=1.73$ and $\mathrm{OsN}=1.63 \AA .95$

Given the paucity of structurally characterized tris(chalcogenido) complexes for heavier chalcogens we undertook a model study of the anion in $\left[\mathrm{Cp} * \mathrm{~W}(\mathrm{~S})_{3}\right]^{-}\left[\mathrm{NEt}_{3} \mathrm{H}\right]^{+}, 6 .{ }^{92}$ Analysis of

(86) (a) Herrmann, W. A.; Wagner, W.; Fleisner, U. N.; Volkhardt, U. Angew. Chem., Int. Ed. Engl. 1991, 30, 1636. (b) Herrmann, W. A.; Fischer, R. W.; Mark, D. W. Angew. Chem., Int. Ed. Engl. 1991, 30, 1638.

(87) Herrmann, W. A.; Herdtweck, E.; Floël, M.; Küsthardt, U.; Okuda, J. Polyhedron 1987, 6, 1165.

(88) Brandon, J. K.; Brown, J. D. Can. J. Chem. 1968, 46, 933.

(89) Day, V. W.; Fredrich, M. F.; Klemperer, W. G.; Shum, W. J. Am. Chem. Soc. $1977,99,6148$.

(90) Krebs, B.; Müller, A.; Beyer, H. H. Inorg. Chem. 1969, 8, 436.

(91) Tatsumi, K.; Inoe, Y.; Nakamura, A.; Cramer, R. E.; Van Dorne, W.; Gilje, J. W. J. Am. Chem. Soc. $1989,111,782$

(92) Lau, M. S.; Kretz, C. M.; Geoffrey, G. L.; Rheingold, A. L. Organometallics 1993, 12, 3447.

(93) Massa, M. A.; Rauchfuss, T. B.; Wilson, S. R. Inorg. Chem. 1991, $30,4667$.

(94) Lotspeich, J. F.; Javan, A.; Englebrecht, A. J. Chem. Phys. 1959, 31, 633.

(95) Pastuszak, R.; L'Haridon, P.; Marchand, R.; Laurent, Y. Acta Crystallogr, 1982, B38, 1427. 


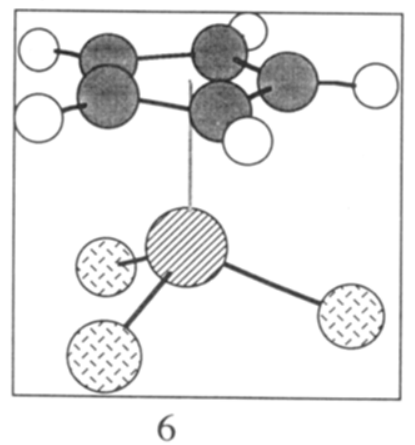

6 can be compared with the isostructural $\mathrm{CpReO}_{3} .{ }^{87}$ The complexes are $C_{s}$ minima although local $C_{3 v}$ symmetry of the $\mathrm{MCh}_{3}$ fragment is apparent. The distance from the Cp centroid to $\mathrm{W}$ is $2.13 \AA$ (2.20 $\AA$, calcd); the average $\mathrm{Re}-\mathrm{C}$ distance in $\mathrm{Cp}^{\prime} \mathrm{ReO}_{3}$ is $2.40 \AA$ ( $2.46 \AA$, calcd). The centroid-WS angles average $113^{\circ}$ in the experimental ${ }^{92}$ and computational models. The $\mathrm{OReO}$ angles are $106^{\circ}\left(\mathrm{av}^{97}\right)$ and $\mathrm{ReO}=1.70 \AA\left(a v^{97}\right)$ in $\mathrm{Cp}^{\prime} \mathrm{ReO}_{3}$ compared with $105^{\circ}$ and $1.68 \AA$, respectively, in the model. Average WS bond lengths are $2.19 \AA$ (experimental ${ }^{92}$ ) and $2.20 \AA$ (calcd). Thus, agreement between ECP results and experimental data is excellent for this rare example of a tris(chalcogenide) moiety incorporating a heavier chalcogenide and the lighter trioxo analogue.

d. $\mathbf{M}(\mathbf{C h})_{4}$ Complexes. The $\mathrm{d}^{0}$ metalates and heavier congeners, $\left[\mathrm{M}(\mathrm{Ch})_{4}\right]^{q-}$, constitute the best studied, computationally and experimentally, class of terminal chalcogenido complexes..$^{2-4}$ Ubiquitous salts such as potassium permanganate ${ }^{2}$ were "wellknown to chemists in the early nineteenth century", while synthesis of thiometalates by introduction of $\mathrm{H}_{2} \mathrm{~S}$ into acidic solutions of molybdate and tungstate was reported by Berzelius as early as $1826 . .^{5 a}$ Some of the earliest computational studies of TM complexes are the studies of tetrahedral $\left[\mathrm{MO}_{4}\right]^{q-}$ complexes by Wolfsberg and Helmholz ${ }^{96}$ employing a predecessor of the extended Hückel method. The greatest amount of data exists for homoleptic $\left[\mathrm{M}(\mathrm{Ch})_{4}\right]^{q-}$ complexes in which $\mathrm{Ch}=\mathrm{O}$ and $\mathrm{S},{ }^{2-5,97}$ although some $\left[\mathrm{M}(\mathrm{Se})_{4}\right]^{9-}$ complexes have been recently characterized. ${ }^{98,99}$ Mixed metalates, $\left[\mathrm{M}(\mathrm{O})_{x}(\mathrm{~S})_{4-x}\right]^{q-}$, $\left[\mathrm{M}(\mathrm{O})_{x}(\mathrm{Se})_{4-x}\right]^{q-}$, and $\left[\mathrm{M}(\mathrm{S})(\mathrm{Se})_{4-x}\right]^{q-}$, are known for $\mathrm{M}=\mathrm{V}$, Mo, W and Re. ${ }^{5}$

Geometry optimized ground states for homoleptic $\left[\mathrm{M}(\mathrm{Ch})_{4}\right]^{q-}$ complexes are tetrahedral, Table 8 . In general, there is excellent agreement between theory and experiment for metalates and tetrathiometalates. For the ten metalates for which there is experimental data, ${ }^{2,3}$ Table 8 , the average error in metal-oxo bond lengths is less than $2 \%$. Similarly, good agreement is found between ECP predicted geometries and experiment ${ }^{5}$ for tetrathiometalates, Table 8. A word of caution is in order regarding the tetrathiometalates of the first row metals, $\left[\mathrm{Cr}(\mathrm{S})_{4}\right]^{2-}$ and $\left[\mathrm{Mn}(\mathrm{S})_{4}\right]^{-}$, since it is observed ${ }^{15}$ that for a family of related TM complexes the appropriateness of single-determinant wave functions tends to decrease as one goes toward the right in the first transition series. Also, the weakening of $\mathrm{M} \mathrm{d} \pi-\mathrm{Ch} \mathrm{p} \pi$ bonding for heavier MG elements can exacerbate the electron correlation problem. However, for the five tetrathiometalates with which one can compare experimental and calculated metric data for metal-sulfido bond lengths, ${ }^{5,97}$ the average difference between theory and experiment is less than $2 \%$.

Tetraselenometalates have recently succumbed to crystallographic analysis. ${ }^{98,99} \mathrm{NbSe}_{4}{ }^{3-}$ and $\mathrm{TaSe}_{4}{ }^{3-}$ have calculated metalselenido bond lengths of $2.46 \AA, \approx 3 \%$ longer than the experimental

(96) Wolfsberg, M.; Helmholz, L. J. Chem. Phys. 1952, 20, 837.

(97) Recently, Lee et al. have focused on simplified syntheses of tetrathiometalates. (a) Lee, S. C.; Holm, R. H. J. Am. Chem. Soc. 1990, 112, 9654. (b) Lee, S. C.; Li, J.; Mitchell, J. C.; Holm, R. H. Inorg. Chem. 1992, 31, 4333 .

(98) Kolis, J. W.; O’Neal, S. C. J. Am. Chem. Soc. 1988, 110, 1971.

(99) Ibers, J. A.; Latroche, M. Inorg. Chem. 1990, 29, 1503. average, Table 8.99 Agreement with crystal data is better for group VIB dianions, $1-2 \%$, Table $8 .{ }^{98}$ Finally, we have calculated the structure of $\mathrm{T}_{\mathrm{d}} \mathrm{WTe}_{4}{ }^{2-} ; \mathrm{WTe}=2.57 \AA$, or $0.23 \AA$ longer than WSe in $\mathrm{WSe}_{4}{ }^{2-}$, similar to that found, experimentally and computationally, for other $\mathrm{Se} / \mathrm{Te}$ congeners (vide supra). The structure of a tetratellurometalate has, to our knowledge, not been reported although given the rapid progress in this area it will not be surprising to see one in the near future. If calculations on lighter metalates are an indication, one can expect the ECP predicted geometry to be in good agreement with this interesting synthetic target.

Mixed thiometalates, $\left[\mathrm{M}(\mathrm{O})_{x}(\mathrm{~S})_{4-x}\right]^{q-}$ have $C_{3 v}(x=1,3)$ and $C_{2 v}(x=2)$ minima. Mixed tetrathiometalates, Table 9 , show $\mathrm{MO}$ bonds to shorten as oxos are replaced with sulfidos, as expected since oxo is a stronger $\pi$-bonding ligand than sulfido. However, calculations show the degree of shortening in metal-oxo bond lengths changes as the metal changes. For $\mathrm{V}$ complexes $\left(\left[\mathrm{V}(\mathrm{O})_{x}(\mathrm{~S})_{4-x}\right]^{3-}\right)$ incrementally replacing an oxo with a sulfido causes the metal-oxo bond to shorten by 0.04 ; for $\left[\operatorname{Re}(\mathrm{O})_{x}(\mathrm{~S})_{4-x}\right]^{-}$ systems the incremental shortening is much less $(0.01 \AA)$ as complexes become more sulfur-rich; Mo and $\mathrm{W}$ complexes are intermediate. These data suggest that metal $\mathrm{d} \pi$-ligand $\mathrm{p} \pi$ bonding weakens in the order $\mathrm{V}>\mathrm{Mo}, \mathrm{W}>\mathrm{Re}$. As the ligands sets are identical it seems reasonable to infer that the changes reflect intrinsic metal $\pi$-bonding power.

\section{Discussion}

In this paper we report a structural analysis of transitionmetal chalcogenido complexes in a variety of geometries and oxidation states. Agreement is very good in the large majority of cases between structures calculated with effective core potential methods and structures determined by X-ray, electron diffraction, and microwave data. The good agreement for heavier chalcogens is of particular interest since it is well accepted that TM $\mathrm{d} \pi-\mathrm{MG}$ $\mathrm{p} \pi$ bonding becomes weaker for heavier MG congeners, ${ }^{2}$ a circumstance which can exacerbate the electron correlation problem. ${ }^{100}$ In a previous study of $\mathrm{TM}=\mathrm{Si}$ complexes, electron correlation was found to be of importance in obtaining even a qualitative description of the TM-Si double bond.15i,j Phosphinidene $\left(\mathrm{L}_{n} \mathrm{M}=\mathrm{PR}\right)$ complexes are intermediate between silylidenes and sulfidos making their study of great interest. ${ }^{15 \mathrm{k}}$ The present paper provides convincing evidence that computational methods employed are adequately describing the electronic structure of these diverse TM-chalcogenido complexes.

Based on orbital overlap arguments ${ }^{2-4}$ the $\mathrm{TM}-\mathrm{Ch}$ bond in the WCl${ }_{4} \mathrm{Ch}$ and $\mathrm{TaCl}_{3} \mathrm{Ch}$ can be considered a triple bond (two orthogonal $\mathrm{d} \pi$ orbitals on the metal can overlap two orthogonal $\mathrm{p} \pi$ orbitals on $\mathrm{Ch}$ ). For metalates there are eight $\mathrm{Ch} \mathrm{p} \pi$ orbitals, clearly too many for all four $\mathrm{Ch}$ to form a double bond so that the WCh bond order must be less than 2, as comparison of WCh bond lengths for $\mathrm{d}^{0}-\mathrm{WCl}_{4} \mathrm{Ch}$ and $\mathrm{d}^{0}-\mathrm{WCh}_{4}{ }^{2-}$ makes clear. Despite the increased coordination number of $\mathrm{WCl}_{4} \mathrm{Ch}$ (ionic radii of $\mathrm{W}^{6+}$ are 0.56 and $0.65 \AA$ for coordination numbers 4 and 5 , respectively ${ }^{101}$ ), WCh bond length in $\mathrm{WCl}_{4} \mathrm{Ch}$ are shorter by $\approx 0.15 \AA$. Additionally, metric and vibrational data for $\left[\mathrm{M}(\mathrm{O})_{x}(\mathrm{~S})_{4-x}\right]^{q-}$, Table 9, highlights the competition for TM $\mathrm{d} \pi-$ $\mathrm{Ch} \mathrm{p} \pi$ bonding in mixed thiometalates: TM-oxo and TM-sulfido bond lengths increase as the complex becomes more oxygen-rich. Interestingly, $\mathrm{WCh}$ bond lengths in $\mathrm{WCl}_{2} \mathrm{Ch}_{2}$, Table 6 , are $\approx 0.03$ $\AA$ longer than those in $\mathrm{WCl}_{4} \mathrm{Ch}$, Table 4 , an observation counter to the lengthening one typically observes for analogous bond types upon increasing coordination number; the fundamental description

(100) A survey of the challenges in computationald-and f-block chemistry, and the approaches employed to address them can be found: (a) Zerner, M. C.; Salahub, D. "The Challenge of d- and f-Electrons;" ACS: Washington, D.C., 1989. (b) Quantum Chemistry: The Challenge of Transition Metals and Coordination Chemistry; Veillard, A., Ed.; Reidel: Dordrecht, 1985.

(101) Porterfield, W. M. Inorganic Chemistry; Addison-Wesley, Reading, PA, 1983; pp 90-92.

(102) Pipek, J.; Mezey, P. Z. J. Chem. Phys. 1989, 90, 4916. 
Table 8.

$\left[\mathrm{M}(\mathrm{O})_{4}\right]^{q-\text { Complexes }^{a}}$

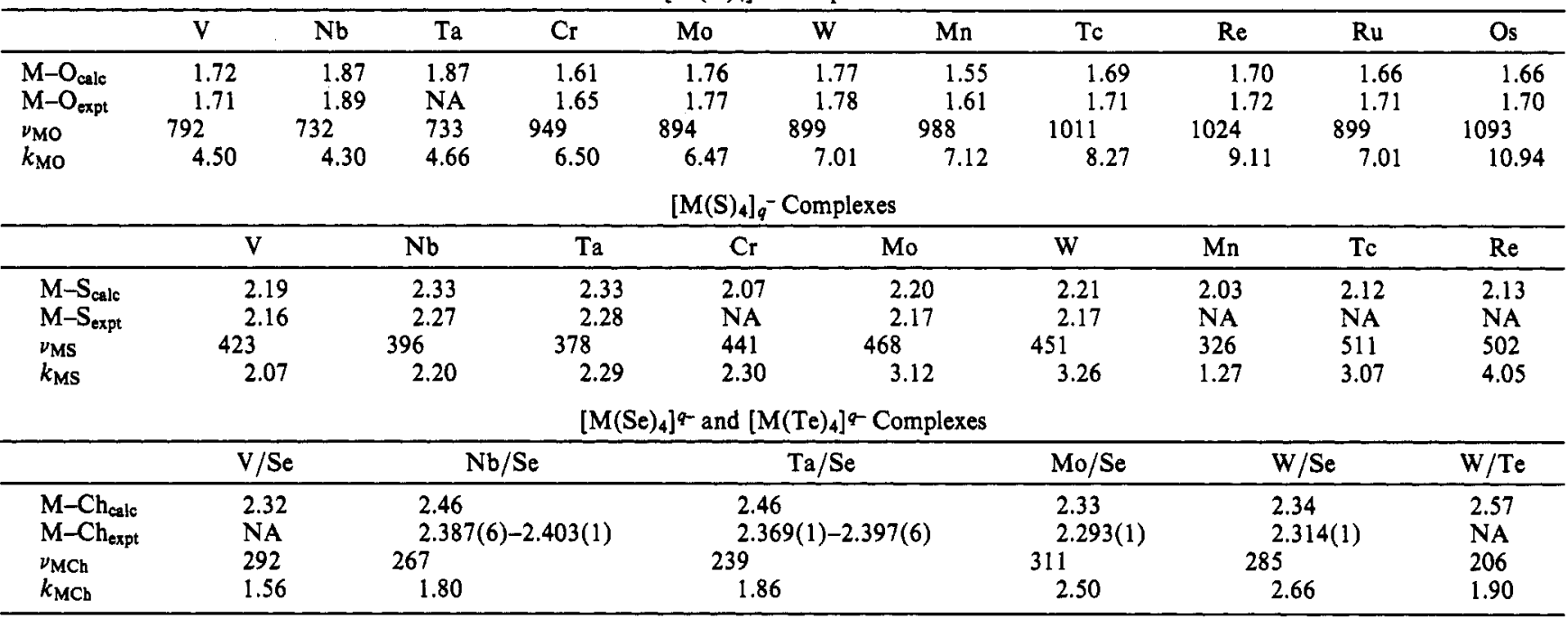

${ }^{a}$ All complexes are $T_{d}$ minima. Experimental data are from refs $2-5,98$, and 99 .<smiles></smiles>

Table 9. Calculated $\left[\mathrm{M}(\mathrm{O})_{x}(\mathrm{~S})_{4-x}\right]^{q-}$ Geometries $^{a}$

\begin{tabular}{|c|c|c|c|c|}
\hline & V & Mo & W & $\mathbf{R e}$ \\
\hline $\begin{array}{l}\text { MO } \\
\text { MS }\end{array}$ & $\begin{array}{l}1.58 \AA \\
2.25 \AA\end{array}$ & $\begin{array}{c}x=1 \\
1.69 \AA \\
2.24 \AA\end{array}$ & $\begin{array}{l}1.70 \AA \\
2.25 \AA\end{array}$ & $\begin{array}{l}1.67 \AA \\
2.14 \AA\end{array}$ \\
\hline$\nu_{\mathrm{MO}}$ & 1054 & 1012 & 1022 & 1067 \\
\hline$k_{M O}$ & 7.97 & 8.30 & 9.06 & 9.88 \\
\hline$\nu_{\mathrm{MS}}$ & 388 & 449 & 433 & 492 \\
\hline$k_{\mathrm{MS}}$ & 1.74 & 2.86 & 3.00 & 3.88 \\
\hline $\begin{array}{l}\text { MO } \\
\text { MS }\end{array}$ & $\begin{array}{l}1.62 \AA \\
2.34 \AA\end{array}$ & $\begin{array}{c}x=2 \\
1.71 \AA \\
2.28 \AA\end{array}$ & $\begin{array}{l}1.72 \AA \\
2.29 \AA\end{array}$ & $\begin{array}{l}1.68 \AA \\
2.17 \AA\end{array}$ \\
\hline$\nu_{\mathrm{MO}}$ & 999 & 988 & 998 & 1063 \\
\hline$k_{\mathrm{MO}}$ & 7.15 & 7.90 & 8.62 & 9.82 \\
\hline$\nu_{\mathrm{MS}}$ & 340 & 427 & 412 & 483 \\
\hline$k_{\mathrm{MS}}$ & 1.33 & 2.59 & 2.72 & 3.75 \\
\hline MO & $1.66 \AA$ & $\begin{array}{c}x=3 \\
1.73 \AA\end{array}$ & $1.74 \AA$ & $1.69 \AA$ \\
\hline MS & $2.46 \AA$ & $2.33 \AA$ & $2.34 \AA$ & $2.20 \AA$ \\
\hline$v_{\mathrm{MO}}$ & 905 & 942 & 948 & 1041 \\
\hline$k_{\mathrm{MO}}$ & 5.87 & 7.19 & 7.79 & 9.40 \\
\hline$\nu_{\mathrm{MS}}$ & 272 & 400 & 387 & 469 \\
\hline$k_{\mathrm{MS}}$ & 0.86 & 2.27 & 2.40 & 3.54 \\
\hline
\end{tabular}

a For $x=2$ the minima are $C_{2 v} ;$ for $x=1,3$ the minima are $C_{3 v}$.<smiles>O[W](O)(S)(S)S</smiles><smiles>O[W](O)(O)(S)S</smiles><smiles></smiles>

of the WCh bond lengths must therefore be different in $\mathrm{WCl}_{2} \mathrm{Ch}_{2}$ and $\mathrm{WCl}_{4} \mathrm{Ch}$. For this reason and given the observation of small competition between $\mathrm{Ch}$ and $\mathrm{Ch}^{\prime}$ in $\mathrm{WCl}_{2}(\mathrm{Ch})\left(\mathrm{Ch}^{\prime}\right)$, see Table 6 , we favor a description of WCh bonds in $\mathrm{WCl}_{2} \mathrm{Ch}_{2}$ which is weighted toward a double bond. A maximum of three TM $\mathrm{d} \pi-$ $\mathrm{Ch} \mathbf{p} \pi$ bonds are possible for a tetrahedral complex, so that $\mathbf{E}$ is not possible, while $\mathbf{F}-\mathbf{H}$ are expected to dominate. Structures $\mathbf{F}$ and $\mathbf{G}$ would make

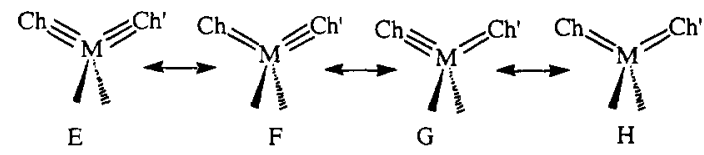

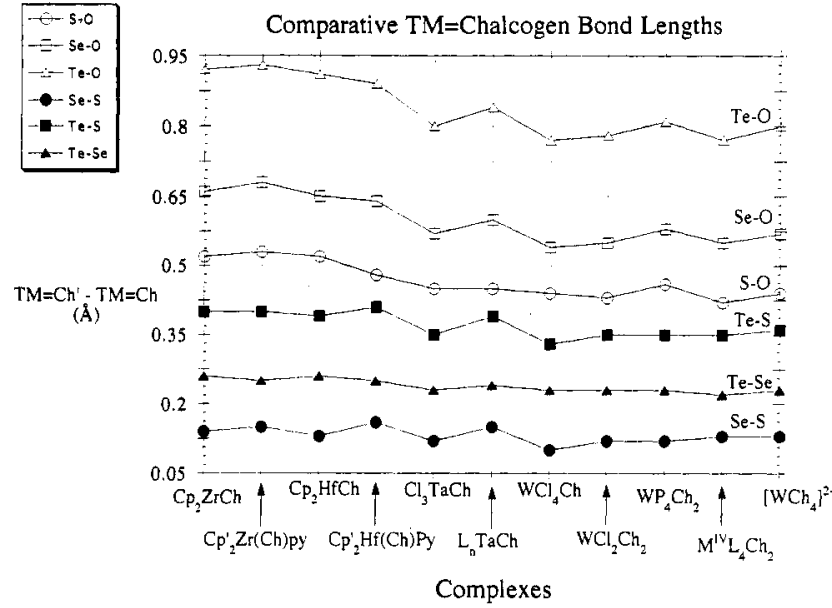

Figure 1. Comparative TM-chalcogen bond lengths $\left(R_{\mathrm{MCh}}-R_{\mathrm{MCh}}\right)$ from experimental $\left(\mathrm{Cp}_{2}^{\prime} \mathrm{Zr}(\mathrm{Ch}) \mathrm{py}, \mathrm{Cp}_{2}^{\prime}{ }_{2} \mathrm{Hf}(\mathrm{Ch}) \mathrm{py}, \mathrm{L}_{n} \mathrm{TaCh}\right.$, and $\left.\mathrm{M}^{1 \mathrm{~V}} \mathrm{~L}_{4} \mathrm{Ch}_{2}\right)$ and calculated (remaining entries) data; see footnotes in Table 10.

equivalent contributions for $\mathrm{Ch}=\mathrm{Ch}^{\prime}$; if $\mathbf{F}$ and $\mathbf{G}$ were major contributors, replacement of $\mathrm{Ch}^{\prime}$ with a stronger $\pi$-bonding ligand (e.g., $\mathrm{WCl}_{2} \mathrm{Se}_{2} \rightarrow \mathrm{WCl}_{2} \mathrm{SeO}$ ) should lead to $\mathrm{F}$ making a much larger contribution and a significantly shorter $\mathrm{WCh}^{\prime}$ bond length (and larger WCh' force constant) which the calculations indicate does not happen, see Table 6. A description such as $\mathbf{H}$ is consistent with the notion that the chalcogenido ligands in $\mathrm{WCl}_{2}(\mathrm{Ch})\left(\mathrm{Ch}^{\prime}\right)$ (and presumably other $\mathrm{d}^{0} \mathrm{cis}$-di(chalcogenido) complexes) exist in relative electronic isolation.

Recent experiments provide an opportunity to probe $\mathrm{TM}=\mathrm{MG}$ multiple bonding bond as a function of position in the Periodic Table. For complexes where there is data for an entire series of nonradioactive chalcogens we hve plotted relative bond lengths $\left(R_{\mathrm{MCh}}-R_{\mathrm{MCh}}\right)$ for experimental and computational models in Figure 1; the data are collected in Table 10. Inspection of Figure 1 and Table 10 shows that other than the $\mathrm{Zr}$ - and $\mathrm{Hf}-$ oxos (experimental and computational models) there is similar behavior in relative bond lengths despite widely varying chemical environments. Relative bond lengths versus oxo ( $\mathrm{S}-\mathrm{O}, \mathrm{Se}-\mathrm{O}$, and $\mathrm{Te}-\mathrm{O}$ in Table 10 ) in group IVB systems tend to be larger than for other families of complexes. Relative bond lengths for heavier 
Table 10. Relative Bond Lengths for Transition-Metal Systems

\begin{tabular}{lcccccc}
\hline \multicolumn{1}{c}{ complex } & S-O & Se-O & Te-O & Se-S & Te-S & Te-Se \\
\hline${ }^{*} \mathrm{Cp}_{2} \mathrm{ZrCh}$ & 0.52 & 0.66 & 0.92 & 0.14 & 0.40 & 0.26 \\
$\mathrm{Cp}_{2}{ }_{2} \mathrm{ZrCh}(\mathrm{py})$ & 0.53 & 0.68 & 0.93 & 0.15 & 0.40 & 0.25 \\
${ }^{*} \mathrm{Cp}_{2} \mathrm{HfCh}$ & 0.52 & 0.65 & 0.91 & 0.13 & 0.39 & 0.26 \\
$\mathrm{Cp}_{2}{ }_{2} \mathrm{HfCh}(\mathrm{py})$ & 0.48 & 0.64 & 0.89 & 0.16 & 0.41 & 0.25 \\
${ }^{*} \mathrm{TaCl}_{3} \mathrm{Ch}$ & 0.45 & 0.57 & 0.80 & 0.12 & 0.35 & 0.23 \\
$\mathrm{~L}_{n} \mathrm{TaCh}^{6}$ & 0.45 & 0.60 & 0.84 & 0.15 & 0.39 & 0.24 \\
${ }^{*} \mathrm{WCl}_{4} \mathrm{E}^{\mathrm{c}}$ & 0.44 & 0.54 & 0.77 & 0.10 & 0.33 & 0.23 \\
${ }^{*} \mathrm{WCl}_{2} \mathrm{Ch}_{2}$ & 0.43 & 0.55 & 0.78 & 0.12 & 0.35 & 0.23 \\
${ }^{*} \mathrm{~W}_{2}\left(\mathrm{PH}_{3}\right)_{4}(\mathrm{Ch})_{2}$ & 0.46 & 0.58 & 0.81 & 0.12 & 0.35 & 0.23 \\
$\mathrm{M}^{1 \mathrm{~V}} \mathrm{~L}_{4} \mathrm{Ch}_{2}{ }^{d}$ & 0.42 & 0.55 & 0.77 & 0.13 & 0.35 & 0.22 \\
${ }^{*}\left[\mathrm{WE}_{4}\right]^{2-}$ & 0.44 & 0.57 & 0.80 & 0.13 & 0.36 & 0.23 \\
\hline
\end{tabular}

${ }^{a}$ Difference in bond lengths for ECP calculated ( $\left.¥\right)$ and experimental TM-chalcogenido complexes. ${ }^{b}$ Experimental $\mathrm{L}_{n} \mathrm{TaCh}$ values were obtained from the following $\mathrm{Ta}^{\mathrm{V}}$ complexes: $\mathrm{Ch}=\mathrm{O}\left(\mathrm{TaO}\left(\mathrm{N}-\mathrm{iPr}_{2}\right)_{3}\right) ;{ }^{2} \mathrm{Ch}$ $=\mathrm{S}$ (average of eight reported $\mathrm{Ta}^{\mathrm{V}}=\mathrm{S}$ complexes), ${ }^{41-43} \mathrm{Ch}=\mathrm{Se}$ and Te (2-Se and 2-Te). $44 \mathrm{a} c$ These are the calculated WCh bond lengths; experimental data for $\mathrm{WCl}_{4} \mathrm{Ch}^{14}$ show similar relative bond lengths for characterized examples $(\mathrm{Ch}=\mathrm{O}, \mathrm{S}$, and $\mathrm{Se})$. Similar agreement is found for the three experimentally characterized members of the $\left[\mathrm{W}(\mathrm{Ch})_{4}\right]^{2-}$ family. ${ }^{d}$ Data for these systems come from $\mathrm{d}^{2}$, group VIB, transbis(chalcogenido) complexes: $\mathrm{Ch}=\mathrm{O}\left(\left[\mathrm{Mo}(\mathrm{O})_{2}(\mathrm{CN})_{4}\right]^{4-}\right) ;{ }^{85} \mathrm{Ch}=\mathrm{S}$ $\left(\mathrm{W}\left(\mathrm{PMe}_{3}\right)_{2}(\mathrm{CN}-\mathrm{t}-\mathrm{Bu})_{2}(\mathrm{~S})_{2}\right) ;{ }^{77} \mathrm{Ch}=\mathrm{Se}\left(\mathrm{W}\left(\mathrm{PMe}_{3}\right)_{4}(\mathrm{Se})_{2} ;^{78} \mathrm{Ch}=\right.$ $\mathrm{Te}\left(\mathrm{W}\left(\mathrm{PMe}_{3}\right)_{4}(\mathrm{Te})_{2}{ }^{\mathrm{I1}}\right.$

Table 11. Relative Bond Lengths for Organic Systems

\begin{tabular}{|c|c|c|c|c|c|c|}
\hline & & $\mathrm{C}-\mathrm{Ch}^{a}$ & $\mathrm{C}=\mathrm{Ch}^{b}$ & $\mathrm{C} \equiv \mathrm{Ch}^{c}$ & & \\
\hline & $\begin{array}{l}O \\
S \\
\mathrm{Se} \\
\mathrm{Te}\end{array}$ & $\begin{array}{l}1.41 \AA \\
1.82 \AA \\
1.96 \AA \\
2.16 \AA\end{array}$ & $\begin{array}{l}1.20 \AA \\
1.61 \AA \\
1.74 \AA \\
1.95 \AA\end{array}$ & $\begin{array}{l}1.13 \AA \\
1.53 \AA \\
1.66 \AA \\
1.88 \AA\end{array}$ & & \\
\hline & $\mathrm{S}-\mathrm{O}^{d}$ & $\mathrm{Se}-\mathrm{O}$ & $\mathrm{Te}-\mathrm{O}$ & $\mathrm{Se}-\mathrm{S}$ & $\mathrm{Te}-\mathrm{S}$ & $\mathrm{Te}-\mathrm{Se}$ \\
\hline $\begin{array}{l}\mathrm{M}-\mathrm{Ch} \\
\mathrm{M}=\mathrm{Ch} \\
\mathrm{C} \equiv \mathrm{Ch}\end{array}$ & $\begin{array}{l}0.41 \AA \\
0.41 \AA \\
0.40 \AA\end{array}$ & $\begin{array}{l}0.55 \AA \\
0.54 \AA \\
0.53 \AA\end{array}$ & $\begin{array}{l}0.75 \AA \\
0.75 \AA \\
0.75 \AA\end{array}$ & $\begin{array}{l}0.14 \AA \\
0.13 \AA \\
0.13 \AA\end{array}$ & $\begin{array}{l}0.34 \AA \\
0.34 \AA \\
0.35 \AA\end{array}$ & $\begin{array}{l}0.20 \AA \\
0.21 \AA \\
0.22 \AA\end{array}$ \\
\hline
\end{tabular}

${ }^{a} \mathrm{ECP}$ calculated $\mathrm{C}$-chalcogen bond length in methanol $\left(C_{s}\right)$ and heavier derivatives. ${ }^{b} \mathrm{ECP}$ calculated $\mathrm{C}$-chalcogen bond length in formaldehyde $\left(C_{2 v}\right)$ and heavier derivatives. ${ }^{c} \mathrm{ECP}$ calculated $\mathrm{C}$-chalcogen bond length in carbon monoxide $\left(C_{\infty}\right)$ and heavier derivatives. ${ }^{d}$ Difference in ECP calculated bond lengths for different bond types; $\mathrm{Ch}-\mathrm{Ch}^{\prime}=R_{\mathrm{CCh}}-\mathrm{R}_{\mathrm{CCh}}$.

$$
\mathrm{C}_{\mathrm{H}}^{\mathrm{C}}-\mathrm{Ch}_{\mathrm{H}}^{\mathrm{Ch}}=\mathrm{Ch} \quad \mathrm{C} \equiv \mathrm{Ch}
$$

chalcogens ( $\mathrm{Se}-\mathrm{S}, \mathrm{Te}-\mathrm{S}$, and $\mathrm{Te}-\mathrm{Se}$ ) show less variation regardless of TM complex. As a further probe, ECP calculations were carried out (using the same approach outlined in Computational Methods) on organic compounds with prototypical single $\left(\mathrm{H}_{3} \mathrm{C}-\mathrm{Ch}-\mathrm{H}\right)$, double $\left(\mathrm{H}_{2} \mathrm{C}=\mathrm{Ch}\right)$, and triple $(\mathrm{C} \equiv \mathrm{Ch})$ bonds. Relative bond lengths for organic systems, Table 11, show similar behavior to non-metallocene complexes in Table 10 . Parkin et al. ${ }^{13}$ have discussed similar considerations based on $\mathrm{ZrCh}$ bond length data for $\mathrm{CpZr}(\mathrm{Ch})(\mathrm{py})$ and our preliminary ECP calculations. Analysis of ECP wave functions for $\mathrm{Cp}_{2} \mathrm{ZrCh}$ in which delocalized RHF molecular orbitals have been transformed into localized variants ${ }^{102}$ clearly points to a greater contribution from a singlybonded $\mathrm{Zr}-\mathrm{Ch}$ structure (relative to $\mathrm{Zr}=\mathrm{Ch}$ ) when $\mathrm{Ch}$ is $\mathrm{O}$ compared to sulfido, selenido, and tellurido analogues. The $\mathrm{ZrO}$ $\pi$-bonds are significantly more localized on the oxoligand. Taken together, the data suggest that in $\mathrm{WCl}_{4} \mathrm{Ch},\left[\mathrm{W}(\mathrm{Ch})_{4}\right]^{2-}$, $\mathrm{WL}_{4}(\mathrm{Ch})_{2}$, and $\mathrm{TaCl}_{3} \mathrm{Ch}$ the nature of the TMCh bond is similar for all chalcogens, while there is a fundamental difference in the $\mathrm{Zr}$-oxo (and $\mathrm{Hf}-\mathrm{oxo}$ ) bond in relation to heavier chalcogens.

In previous studies of $\mathrm{TM}=\mathrm{MG}$ complexes ${ }^{15}$ we have focused on the a bility of ECPs to make computations feasible for complexes incorporating transition metals from the lightest to heaviest members of a triad. Transition metals studied here include the entire portion of the transition series for which multiply-bonded chalcogenides have been structurally characterized, i.e., Tithrough Co-triads. The present work also evaluates ECP methods
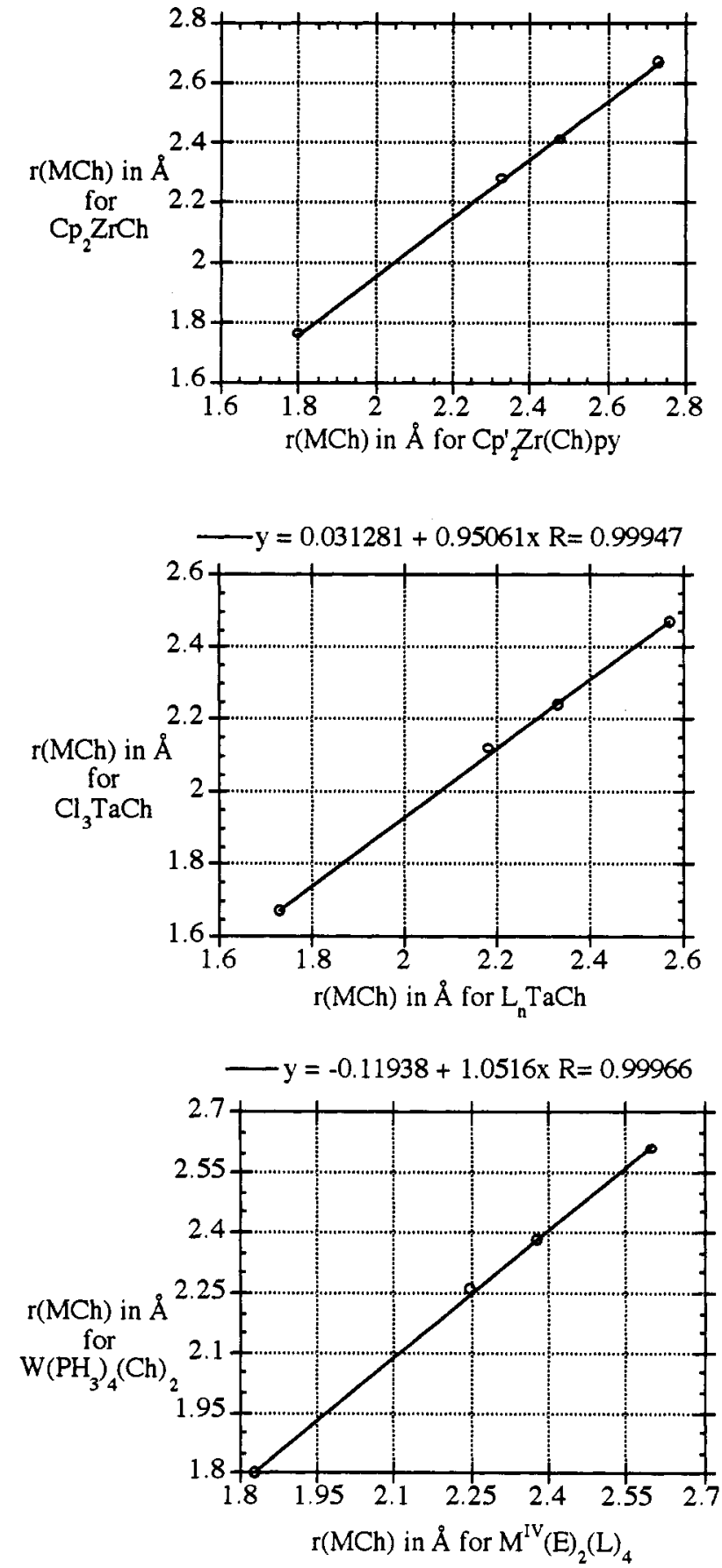

Figure 2. Plots of calculated versus experimental TM-Ch bond lengths for models in which the entire series of nonradioactive chalcogens have been experimentally determined.

as a tool for addressing the chemistry of heavier MG elements. All nonradioactive chalcogens (i.e., $\mathrm{O}, \mathrm{S}, \mathrm{Se}, \mathrm{Te}$ ) are included in the ECP study. With few exceptions, agreement between theory and experiment is excellent. In Figure 2 calculated versus experimental bond lengths are plotted for complexes in which there is an entire series of chalcogenidos $(\mathrm{Ch}=\mathrm{O}, \mathrm{S}, \mathrm{Se}, \mathrm{Te})$ : $\mathrm{Cp}_{2} \mathrm{ZrCh}$ vs $\mathrm{Cp}^{\prime}{ }_{2} \mathrm{Zr}(\mathrm{Ch})$ (py) ( $\mathrm{Cp}_{2} \mathrm{HfCh}$ vs $\mathrm{Cp}^{\prime} 2 \mathrm{Hf}(\mathrm{Ch})(\mathrm{py})$ shows equally good agreement), $\mathrm{Cl}_{3} \mathrm{TaCh}$ vs $\mathrm{L}_{n} \mathrm{TaCh}$, and trans$\mathrm{W}\left(\mathrm{PH}_{3}\right)_{4}(\mathrm{Ch})_{2}$. Inspection of linear least-squares fit lines in Figure 2 shows the slopes and correlation coefficients to be near unity, while intercepts are close to zero. Additionally, complexes for which three members $(\mathrm{Ch}=\mathrm{O}, \mathrm{S}, \mathrm{Se})$ have been experimentally characterized, e.g., $\mathrm{WCl}_{4} \mathrm{Ch}^{14}$ and $\left[\mathrm{M}(\mathrm{Ch})_{4}\right]^{2-, 2,5,98,99}$ also show good agreement with calculated data for heavy and light chalcogens (vide supra). The satisfactory results and growing 
importance of heavier MG elements in electronics and materials applications suggests that the study of TM complexes involving the heavier chalcogens with effective core potentials will be a fruitful area of computational research in the future.

Acknowledgment. The authors acknowledge IBM (Developers Discount Program), the National Science Foundation (through grant CHE-9314732 and their support of Cornell National Supercomputer Facility, San Diego Supercomputing Center, and National Center for Supercomputing Applications), the Joint Institute for Computational Science (a coalition among the University Tennessee-Knoxville, Oak Ridge, Vanderbilt, and Memphis State to encourage the use of high-performance computing in Tennessee), Memphis State University (Faculty Research Grants (93-10305) for oxo research), and the Air Force Office of Scientific Research for their support of effective core potential studies of d-block chemistry at Memphis State. The authors also thank Doug Baldwin, Stacey Toney, and Timara Faulkner (all at Memphis State) for carrying out a few of the calculations described here. Finally, we would like to thank Profs. John Arnold (Berkeley), Pat Desrochers (Central Arkansas), Ged Parkin (Columbia), and Jim Mayer (Washington) for the communication of unpublished results and helpful discussions, particularly those regarding the chemistry of the heavier chalcogenides. 